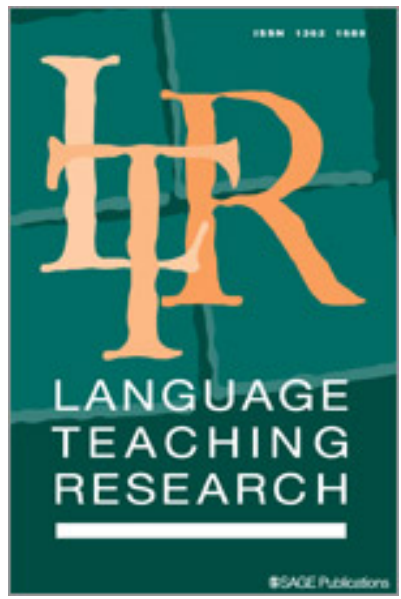

\title{
The complexity of control shift for learner autonomy: A mixed-method case study of Chinese EFL teachers' practice and cognition
}

\begin{tabular}{|c|l|}
\hline Journal: & Language Teaching Research \\
\hline Manuscript ID & LTR-20-0025.R1 \\
\hline Keywords: & $\begin{array}{l}\text { learner autonomy, control shift, Chinese EFL classroom innovation, } \\
\text { language teacher cognition, teaching practices }\end{array}$ \\
\hline Abstract: & $\begin{array}{l}\text { The promotion of language learner autonomy has been recognised as } \\
\text { being beneficial in various domains, from linguistic achievement to } \\
\text { personal growth. Key to the development of learner autonomy is shifting } \\
\text { control from the teacher to the learner. While much has been written } \\
\text { about the construct of learner control, there has been little close } \\
\text { examination of the practices with which language teachers release their } \\
\text { command. This paper reports on a study conducted in a Chinese private } \\
\text { school intent on promoting learner autonomy, and explores ways in } \\
\text { which teachers' practices facilitated or hindered control shift and their } \\
\text { perceptions of these actions. From a study of nine teachers within one } \\
\text { English department, two case studies are explored in depth through } \\
\text { analysis of classroom practices, interviews and post-lesson discussions. } \\
\text { While the feasibility of promoting learner autonomy in non-Western } \\
\text { contexts has previously been questioned, the present findings highlight } \\
\text { the opportunities available within routine tasks, while stressing the } \\
\text { delicacy of these opportunities. }\end{array}$ \\
\hline & \begin{tabular}{l} 
\\
\hline
\end{tabular} \\
\hline
\end{tabular}

\section{SCHOLARONE" Manuscripts}




\title{
The complexity of control shift for learner autonomy: A mixed-method case study of Chinese EFL
} teachers' practice and cognition

\begin{abstract}
The promotion of language learner autonomy has been recognised as being beneficial in various domains, from linguistic achievement to personal growth. Key to the development of learner autonomy is shifting control from the teacher to the learner. While much has been written about the construct of learner control, there has been little close examination of the practices with which language teachers release their command. This paper reports on a study conducted in a Chinese private school intent on promoting learner autonomy, and explores ways in which teachers' practices facilitated or hindered control shift and their perceptions of these actions. From a study of nine teachers within one English department, two case studies are explored in depth through analysis of classroom practices, interviews and post-lesson discussions. While the feasibility of promoting learner autonomy in non-Western contexts has previously been questioned, the present findings highlight the opportunities available within routine tasks, while stressing the delicacy of these opportunities.
\end{abstract}

\section{Introduction}

Since the pioneering work of Holec (1981), language learner autonomy (LA) has been widely advocated, with perceived benefits going beyond linguistic and more general educational outcomes to include healthy personal and societal development (Benson, 2011). Given the core LA principle of learner control (Benson, 2001, 2011), the key action is shifting control from teachers to learners. However, this shift remains little explored in practice amidst a lack of empirical studies investigating teachers' understandings of the concept of LA (Borg \& Al-Busaidi, 2012) and a lack of "deeper qualitative analyses ... of how teachers conceptualize and promote [it]" (Borg \& Alshumaimeri, 2019, p. 29). This paper addresses this gap by reporting on a longitudinal case study in a Chinese school context.

China's Basic Education Curriculum Reform (China MoE, 2001) explicitly specifies LA as a key curricular goal, aiming to move classroom instruction from a routine of students' passively receiving information to one characterised by active learning and development through autonomous and collaborative inquiry. The Reform calls on teachers to create the conditions and opportunities for this to occur (China MoE, 2001). However, teacher education in this aspect has lagged behind, with most new teachers who join the profession lacking knowledge and skills in LA-oriented pedagogies (Wang $\& \mathrm{Ma}, 2009)$. In the meantime, LA initiatives have been promoted at schools throughout the country, with practitioners and administrators exploring approaches for student autonomy, collaboration and inquiry. As a result, by 2011, ten years into the Reform, intensive debate arose regarding the outcomes and effectiveness of the innovations, with views tending to be unfavourable and with teachers expressing frustration and irritation (Xu \& Wong, 2011).

Exploring both practice and cognition in a Chinese school context, this study aims to probe complexities in teachers' implementation of LA, their underlying rationales, and their understanding of the concept, with a view to identifying practical implications.

\section{Literature review}

\section{Learner autonomy and control shift}

Benson's (2001, p. 47) definition of LA in terms of control, specifically "the capacity to take control of one's own learning", provides for empirical observation of LA in the behaviour of teachers and learners (cf. 'learners' taking charge', Holec, 1981; see also Benson, 2011). Subsequent elaboration 
specifies that control involves "having the power to make choices and decisions and acting on them", and further identifies three components of the capacity for control: "ability, desire and freedom" (Huang \& Benson, 2013, p. 9, italics in original). Author1 (2017b) notes a fourth aspect: learners' prior awareness of the possibility of learner control. Thus conducive conditions for LA prototypically exhibit the following features: learners know they could and should take control of their learning; they want to; they are able to; and they have the freedom and opportunities to do so.

The shift of control from teachers to learners is a complex, delicate, and challenging process. It is one in which the teacher's power is decreased while "the learner's power [is] concomitantly increased" (Voller, 1997, p. 106) in what may be conceived as a continuum or series of continua (Candy, 1999). Candy further emphasises the deliberate, conscious nature of the teacher's "surrendering of certain prerogatives" and the necessity of learners accepting the responsibility offered. While ideally a simultaneous and seamless process, this handover may not come naturally, and in actuality may require considerable thought and mediative work. The operation of such mediation is, however, scarce in existing literature.

The complexity and delicacy of control shift increases when the teacher's relinquishment is considered in terms of its quality and extent. Candy (1991) highlights the risk of "pseudo-autonomy" (p. 238), when teachers merely go through "the motions of devolving responsibility onto learners" without "commitment or conviction" (p. 237), while Benson $(2001,2011)$ raises the issue of effectiveness in power transfer, in terms of whether the freedom offered is "genuine" and whether learners' decisions have "real consequences" (2011, p. 165). Dam (2011) further identifies other familiar pitfalls encountered by teachers' wishing to embrace LA, such as lack of confidence in students, ingrained habits of teaching rather than supporting, and ready excuses such as "time constraints and having to use a coursebook" (pp. 49-50).

Further complexity and challenges arise in relation to how learners assume control, especially in collaborative groupwork when control is shared among heterogeneous learners. It is generally believed that groupwork shifts the focus from the teacher to students, enhancing learner participation and responsibility (Dam, 2011), creating opportunities for learner interaction and interdependence (Kohonen, 2010) and reducing anxiety (Peterson, 2012). However, there remain concerns relating to quality or effectiveness of learner control, such as pairs not necessarily collaborating (Storch, 2001) and groupwork enabling dependency (Lee, Smith \& Sergueeva, 2016). Concerns have also been raised as to the appropriateness of collaborative learning within the Chinese context (Chen \& Hird, 2006).

As Little (2007a) notes, there has also been considerable debate over the cross-cultural transferability of LA, with claims that it is heavily laden with Western values. Further, even if LA is in principle universally relevant, Benson (2011, p. 70) points out that the associated pedagogical practices may not be. Specifically relating to China, it has been argued that Chinese cultural traits represent "an obstacle" (Ho \& Crookall, 1995, p. 235) to LA, while some Chinese scholars have criticised uncritical adoption of Western concepts (Shu \& Hua, 2009) or failure to contextualise the notion of LA (Shu, 2004).

An alternative position holds that LA has points of genesis in both the East and West which have been nourished in the interaction between the two. Examples are seen in the ancient fundamental Taoist principle of zi zhi (self-governing) and its impact on Carl Rogers (an important source of LA theory, as identified by Benson, 2001), the manifestation of LA in the works of Confucius and Zhu Xi (11301200) (Jin \& Cortazzi, 2006), and belief in real-life active learning as espoused by $20^{\text {th }}$ century education reformer Tao Xing-Zhi, student of Dewey. Thus the notion of LA is well-grounded in Chinese traditions, supporting the legitimacy of current efforts to promote it. 
For empirical research, the sub-issue of capacity for control (awareness, desire, ability and freedom) and pitfalls in control handover (e.g. pseudo-autonomy) provide a starting point for further observation and inquiry. In the present study, evidence and counter-evidence of LA will be identified in learner involvement (e.g. Benson, 2003), authentic target-language use (e.g. Dam, 1995), learner awareness-raising (Nunan, 1997) and reflection (e.g. Little, 2007b), and indications of genuine control release and appropriate learner support (Benson, 2011; Candy, 1991). Learner involvement will include responsibilities in the learning process, including identifying needs and setting goals, selecting resources and methods, defining progression and monitoring progress, and assessing outcomes (Holec, 1981; Reinders, 2010). These features provide observable evidence of actions promoting LA, allowing us to address the lack of empirical evidence in previous studies (Borg \& Alshumaimeri, 2019).

\section{Teachers' cognition and practice about learner autonomy}

To explore teachers' cognition and practice regarding learner autonomy, this paper adopts Borg's (2003) holistic view of teacher cognition, defined as "the unobservable cognitive dimension of teaching - what teachers know, believe, and think" (2003, p. 81), whereby knowledge, belief and thinking are considered an inseparable unit of teachers' mental lives. Teacher cognition research seeks "to understand teachers' minds and emotions and the role these play in the process of becoming, being and developing as a teacher" within broad and complex accounts of their "personal, professional, social, cultural and historical contexts" (Borg, 2019, p. 1167). This aligns with the purpose of the study, in which the aim is not to define teachers' cognitive world or to label its different components, but to understand its complexities, particularly in relation to developing LA through the shift of control, and how teachers' beliefs manifest in, and impact on, their classroom practices. On the whole, teacher cognition is conceived as a dynamic (Woods \& Çakır, 2011) complex system, with personalised, practically-oriented, and context-sensitive features (Borg, 2003). The personalised aspect emphasises the individuality of teachers and their own unique cognitions of varying types and involving different subjects (Feryok, 2010). The orientation towards practice highlights the relationship between teacher cognition and classroom actions, which are "reciprocal, rather than deterministic" (Borg, 2018, p. 86). Both cognition and practices involve multiple dimensions - for example, stated and enacted beliefs; observed or reported practices - which evolve over time (Borg, 2018).

Following Camilleri (1999), the last decade has witnessed an upsurge in empirical studies of teachers' LA-related cognition and practice. With two comprehensive reviews available (Borg \& Alshumaimeri, 2019; Author1, 2016), we focus here on three of the more recent and perhaps influential studies. The first, Borg and Al-Busaidi (2012), highlighted the value in researching teachers' knowledge and beliefs about LA, while lamenting the dearth of such work. Their 37-item questionnaire examined teachers' understandings of LA from technical, psychological, social and political perspectives. This soundly developed and comprehensive survey was subsequently employed in further studies, including a volume of partial replications (Barnard \& $\mathrm{Li}, 2016$ ) conducted across eight Asian countries. Importantly, these also explored the follow-up professional development workshops, with some (e.g. Wang \& Wang, 2016) leading to further practitioner research, enhancing the practical value of this research. The third, Borg and Alshumaimeri (2019), provides a major contribution in capturing individual English language teachers' conceptualisations of LA "on an institutional scale" and "in a representative manner" (p. 29) through examination of the largest sample to date (359 EFL teachers from one university; $78 \%$ response rate). Nevertheless, as the authors state, a limitation of both this and nearly all previous studies is the lack of qualitative evidence "of how teachers conceptualize and promote learner autonomy", particularly in relation to observation data. Of the 21 studies that Borg and Alshumaimeri (2019) reviewed, only one (Martinez, 2008) involved observation, with the participants being teacher trainees. Borg and Alshumaimeri (p. 29) reiterate that 
a mixed methods approach (see Creswell \& Plano Clark, 2011) would enhance research into teachers' beliefs and practices about LA.

To briefly summarise, then, previous studies highlight the value of LA and emphasise the key role of control shift, a process requiring careful handling. To date, however, there has been little exploration of how control shift happens in practice and a lack of qualitative analyses, particularly of observation data, to support existing research into teachers' LA-related cognition. On these bases, the following research questions were posed:

1) How and to what extent was control shift reflected in the teachers' practices for promoting learner autonomy?

2) How did the teachers perceive their control-related actions and the concept of learner autonomy?

\section{Methodology}

To explore the present research questions, a case study approach was adopted within an interpretative naturalistic paradigm. The following subsections outline the research setting, participants, and methods of data collection and analysis.

\section{Research setting}

The research site was a private secondary school in northern China with approximately 600 students boarding on campus. An approach was made to the school following a colleague's recommendation of the principal's vision and commitment to learner centred education. Central to the school's special character was its treatment of English as a core subject (alongside Chinese and mathematics), as reflected in its name (\#\# Foreign Language School). Nevertheless, like those in public schools, students followed the national curriculum and focused on the national Zhongkao and Gaokao exams (high school and university entrance exams). Classes comprised 24-36 students each (compared to typically 40-60 in state schools), all native speakers of Chinese. The principal was a nationallyrecognised school administrator with considerable experience and a US-obtained doctorate in education. The founding principle of the school was to combine academic success with well-rounded personal development. To this end, the school's guiding document specified three aims: collaboration, efficiency, and - most notably for present purposes - LA. These were supported by documented education principles, classroom implementation procedures, and measures to support teachers (for details see Author1, 2017b). The implementation of such policies was guided by the academic director, who had been recruited mainly on the basis of his previous experience promoting LA.

Being a private school, students were mostly from the middle- or upper-economic bracket, and the higher tuition fees undoubtedly raised parental expectations of educational quality. Being a private school also allowed for greater freedom in the recruitment and management of staff (e.g. higher salaries and an internal performance-review-and-reward system). Most teachers held a bachelor's degree and many brought substantial skills and experience as programme leaders. Overall, then, the school appears to represent the type of extreme and unique case which usefully serves as a "test bed" (Robson, 2002, p. 182), such that it may fairly be assumed that if the school's attempt to develop LA was ineffective, then the odds are against its success elsewhere.

An interesting feature of the school were the scheduling of weekly 'open lessons'. These were open in the sense of having an open-door policy for anyone to observe the designated teacher's lesson, including outsiders such as parents. Other English teachers were obliged to attend, and it was understood that management and teachers from other departments would also attend on occasion. Each open lesson was followed by a feedback session, which typically involved a rather frank critique and suggestions for development (Author1, 2017a). Each teacher conducted at least two open lessons 
per semester. As a source of observation data, there are three particularly notable aspects of these lessons and discussions. Firstly, since open lessons were by definition scheduled for observation entirely independently of the researcher's presence, there is a stronger sense of ecological validity than typically found in similar studies. Secondly, while events do unfold differently under observation (the observer's paradox), this is somewhat mitigated by open lessons being a routine practice at the school. Thirdly, since the feedback was often rather direct and critical, it may be presumed that teachers were presenting lessons designed to showcase their understanding and application of LA principles and/or groupwork features; it may be that their ordinary practices were less reflective of LA than witnessed in the open lessons.

\section{The participants}

The school's nine English teachers were informed of the project at a staff meeting and all volunteered to participate, thereby enabling a case study of a full academic department. Their willingness to do so probably reflects their experience and familiarity with observation: the researcher was just another observer on the day. Also participating in the broader study were the principal and academic director, both strong advocates of LA. Each teacher taught two classes (twenty 40-minute lessons per week) and was also assigned peer observations and subsequent feedback sessions (3-4 hours per week). Details about the teachers' qualifications, experience and positions within the school are presented in Table 1 (Appendix 1).

\section{Data collection procedures}

Data were collected over an entire 18-week semester through classroom observations (videorecorded; mainly open lessons), audio recordings of post-lesson discussions and individual interviews, and documentary analysis (e.g. curriculum, lesson plans). All nine teachers were observed at least twice each, totalling 22 observed lessons (nineteen open lessons; three ordinary lessons). Also recorded were the scheduled post-lesson peer feedback sessions, and in fourteen cases these were followed by one-to-one discussions with the lead researcher. At the conclusion of the semester, a final interview was conducted with each teacher, and it was only at this point that the research focus on LA was revealed to the participants. Additional interviews were conducted with the principal (once) and the academic director (twice). The discussions and interviews were conducted in Chinese.

\section{Data analysis}

Data analysis was based on Glaser and Strauss' (1967) Grounded Theory and facilitated by NVivo 10. To examine control transition, it was important to firstly make sense of the 22 lessons in terms of broad themes and components. To this end, videos of each lesson were coded minute-by-minute from various perspectives, with links made to observation notes. These codes were tabulated in various ways, amongst which, three tabulations proved particularly insightful: (1) an overview of all the 22 lessons showing the learning tasks of each lesson (e.g. 'reviewing grammar rules for plural nouns') and the allocated times, (2) closer analysis of each major task focusing on how it was conducted in terms of phases and participant roles, from which three main teaching approaches were identified (discussed below), and (3) closer scrutiny of each approach to identify the nature and degree of learner involvement (e.g. self-study; group/pair work). These provided valuable insights into the overall organisation of activities within the classroom and as a way of identifying and classifying lesson phases. Example extracts from the latter two tabulations are provided in Appendices 5 and 6.

Once the broader scope had been established, focus then turned to transcription and close turn-by-turn analysis of actions within particular episodes that seemed ostensibly LA-related. As illustrated in the findings, particular attention was paid to indications of teacher and learner control and other LArelated factors such as actions and responses (e.g. directives and verbal/physical responses), language choice (Chinese or English), and authentic language use.

Interviews and post-lesson discussions were transcribed in full and, with school documentation, were analysed thematically through processes of open and axial coding (Charmaz, 2006; Strauss, 1987), 
constant comparison (Harding, 2013; Strauss, 1987), and iterative checking (Seidel, 1998). Where these directly related to specific actions within lessons, links were made within NVivo. Within the wider project, the accuracy of data transcriptions and quality of data analysis were monitored throughout by doctoral supervisors. Specifically for the purposes of this paper, the data analyses were conducted and agreed upon by both authors, thereby combining the insider perspective of the first author (who spent months 'on the ground' at the research site) with the outsider perspective of the second author. Throughout this process, we challenged one another for robust evidence for all claims and actively sought counter evidence.

\section{Findings}

This section reports findings about the English teachers' practices and cognitions in relation to promoting LA, first in brief overview of all nine teachers' practices (observed and reported) and then in greater detail for two teachers (T2 and T3). Data sources are coded as follows: observation (O), post-lesson discussions (PLD), departmental open discussions (OD), interviews (I), and field notes (FN). The observation data reveal classroom practices, with other sources revealing the teachers' rationales for the practices and their general understanding of the notion of LA.

\section{Observed and reported practices: An overview}

Observation of teachers revealed three common approaches which appeared potentially conducive to the development of LA through promoting students as the main agents of activity. Here, these are labelled pre-lesson presentations, collaborative group learning and student-led peer teaching. The pre-lesson presentations were lesson starters in which students, individually or in teams, presented on a topic that was independent of the main body of the lesson. Introduced by Teacher 1 and subsequently adopted by eight of the nine teachers, students were involved in such ways as selecting or developing their own topics and resources, presenting (individually or in teams) followed by questioning and answering, vocabulary teaching, peer error-correction and performance evaluation. Collaborative group learning, as it was labelled within the school, had been introduced by the academic director as an instructional model to support LA and was used by all teachers. It involved phases of individual self-study, group discussion, group presentation, peer feedback, peer evaluation, and individual internalisation; these were labelled by the director as six phases in a collaborative knowledge construction cycle. An extension of this, adopted by three teachers, was student-led peer teaching, in which students (co-)planned and delivered an assigned teaching task (for details, see Author1, 2016).

Other apparently LA-facilitating practices were discussed by teachers but not observed. These have been grouped into five types and are presented in Table 2 (Appendix 2). Examples include students monitoring one another's progress through peer dictation and text recitation, comparing answers and tackling errors together, peer marking and feedback-giving, and developing autonomous and collaborative study skills. Although not observed, they were reported to be routine; the detailed manner in which they were described suggests that they were at least used on occasion. Overall, it appears that substantial efforts were directed towards creating opportunities for active learner involvement.

Findings from a detailed scrutiny of all 22 observed lessons are presented in overview in Table 3 (Appendix 3) in terms of the approaches different teachers adopted and the LA features embedded in each approach. This makes possible a broad characterisation of each teacher's attempts at promoting LA. For example, as will be discussed in more detail, the promotion of student involvement appears deeply embedded in Teacher 2's (T2) practices, extending to areas not observed or reported for the other teachers. Conversely, the practices of another teacher (T6) appeared to have little student 
involvement, suggesting little orientation towards genuine LA development despite utilising the three LA-conducive teaching approaches common within the school.

In what follows, we examine more closely the practices and beliefs of two teachers. In examining less successful LA-promotion, we leave aside T6, who allowed for minimal student control, and T7 and T9, who seemed reluctant to adopt the promoted groupwork instructional model; we opt instead for T3, who professed to strongly support LA but whose actual practices seemed contradictory. Attention then turns to T2, who appeared to have the most deeply embedded LA practices.

\section{T3: "Maybe, unconsciously, I'm quite dominant"}

Among all the teachers, Teacher 3 (T3) appeared the most enthusiastic in both welcoming and implementing the school's teaching innovation, particularly in relation to the director's group study model. Over the semester, she frequently utilised groupwork, with considerable emphasis on discussion and presentation, together with the awarding of 'points' for worthy performance in a manner closely resembling the director's model. She was later selected to represent the department as one of two 'best groupwork practitioners' in a school teaching competition showcasing the promotion of LA. However, analysis suggests that her practices supported LA in only very superficial ways and at times actually subverted it. In illustrating these practices, we narrow our focus to close analysis of episodes within one phase (presentations), within one particular lesson.

\section{Episode 1}

The episode below illustrates a typical example of T3's employment of the group study model. This occurred at the start of a lesson in a phase lasting approximately fifteen minutes. The activity was a group presentation on plural noun rules, conducted in four steps. First, two or three students from each group wrote the grammar rules on the blackboard. Another group member then led the class review with explanations and/or examples; T3 termed this the presenting/showing (zhan shi) session. Other students were then invited to comment, termed the questioning session. In the fourth step, the teacher awarded groups points for contributions she judged to be valid (T3.L1.O). Below, and elsewhere, italics indicate a translation of the original Chinese (with full scripts presented in Appendix 4).

\section{Observation Extract T3.L1.E1}

01 S1: Group Zhang [a surname] is to present, er, er, the general ones are [T interrupted]

02 T: What is your presentation about?

03 S1: categories, forming methods

04 T: categories, forming methods of what?

05 S1: nouns

06 T: What kind of nouns?

07 S1: er er er, categories, forming methods of plural nouns

$08 \mathrm{~T}$ : uncountable nouns' plural forms?

09 S1: plural nouns

10 T: Ok, go. make it clear.

11 S1: -s, for general nouns, add -s, book, books, bed, bed[s], and boy, boys

......, words with consonants //IIII

12 T: You can look at the word following

13 S1: er er er

$14 \mathrm{~T}$ : Its rule is summarised from special words, look at family, how is it changed? ok?

15 S1: / er er er // add er, er er

16 T: Ok, don't be nervous. Don't be nervous, you can't do it, it's ok. go on.

17 S1: Just this one?

18 T: $\quad$ Yes $\uparrow$

19 S1: er family, families, oh, no 
As confirmed in the post-lesson discussion (T3.L1.PLD), this episode illustrates T3's adoption of three phases of the director's suggested group study model: presentation (written and oral), peer feedback, and evaluation. For present purposes, two main issues are worth noting. Firstly, the working language (written and spoken) was Chinese, with English minimally used and limited to the actual words/examples being presented; this lack of opportunities for authentic language use conflicts with principles of LA. Secondly, the presentation adhered to a highly structured and routinised format directed by the teacher, as suggested by her use of formulaic remarks for opening (Group X is to present), closing (That's all for Group X's presentation), and making additional points (Group X to $a d d$ ). Indeed, her directive comments appeared to have a puppeteer-like control over student movement, suggesting a well-drilled routine with little room for students to initiate independent actions. For example, when shortly after she said "Now, discuss", students responded promptly, heads huddled closely together, suggesting they knew exactly when to talk, to whom and about what; similarly, when the teacher announced that the presenting phase was to start, the three groups at the back of the classroom flocked to the front and crouched down; and when one group was presenting, representatives of other groups queued for their turns (T3.L1.FN). These actions caught attention because they so closely mirrored the director's "groupwork operational tips" (Teacher Training Booklet. \#7.8). Such highly structured sequences of activity are strongly suggestive of the students having been trained in how to respond to the teacher's cues, especially given their occurrence at the start of semester. The highly constrained nature of the activities suggests extremely limited opportunity for student control.

Teacher 3 provided her rationales in the post-lesson discussion, though these were not aligned with her actual practice. First, she expressed great enthusiasm for the group study model, which she said suited her teaching style very well. She expressed confidence that her students loved group work and participated actively. She cited the following saying about idea-exchange: If you have an apple and I have an apple and we exchange apples, then you and I will still each have one apple. But if you have an idea and I have an idea and we exchange these ideas, then each of us will have two ideas ${ }^{1}$ (T3.L1.PLD). She also expressed a distinctly positive attitude towards the group work formalities, as indicated in the following statement of purpose: "Students of this age are lively by nature and full of

\footnotetext{
${ }^{1}$ Originally, by George Bernard Shaw (https://en.wikiquote.org/wiki/Talk:George Bernard Shaw); T3 did not mention the source.
} 
energy, so get them moving, and keep them busy; huddling heads together was like a signal, which put them into immediate action" (T3.L1.PLD). She believed the 'questioning' session provided opportunities for students to learn from one another's strengths and weaknesses, and she particularly highlighted the importance of "learning from mistakes": "I welcome students' mistakes. The more exposed, the better. If they could spot and correct the mistakes in everyday study, they won't get it wrong again in exams" (T3.L1.PLD). In addition, she felt the feedback session could "hold students' attention" and therefore "enhanced students" participation and engagement". The awarding of points was intended as a means of peer evaluation which would facilitate autonomy through critical thinking; in practice, she often awarded the points herself and only did so for strong performance "to see how well students had mastered the learnt knowledge" (T3.L1.PLD).

\section{Episode 2}

The strong sense of teacher control is supported in analysis of the following extract, involving a 'tugof-war' with the third presenter. This followed a sudden and arbitrary decision by the teacher that this particular student (unlike previous ones) should perform his presentation without reference to the group's blackboard notes. This occurred in the midst of the presentation session, following the second presenter's turn. At the beginning of this extract, the student was about to start; the phrase "this time" (Turn 01) refers to the third presentation by the group. Bold indicates vocal emphasis:

\section{Observation Extract T3.L1.E2}

$01 \mathrm{~T}$ Ok, now Group Yue, [...] Now they've presented for two times, now this time, [xxx], you'd better tell us without looking at the blackboard. Do you understand?

02 S4 Yes. [S4 was about to start].

$03 \mathrm{~T}$ You'd better tell us without looking at the blackboard. Without, without looking at the blackboard [T using gestures to illustrate the idea not to look at the blackboard.]. You just look at us. Yes $\uparrow \mathrm{Ok}$, go.

[S4 turned to the blackboard and was to start.]

04 T Don't, don't look at the blackboard [T's voice raised sharply]. Look at us. Yes $\uparrow$ Ok. Look at us.

05 S4 Er, er [S4, still looking at the blackboard, was starting to read.]

06 T No. Without. [T using gestures to illustrate the idea not to look at the blackboard; ss laugh.] Don't look at the blackboard. Yes $\uparrow$ Ok. Go.

07 S4 Group Yue is to present [...] [S4 ignores T's instruction and starts to read from blackboard.]

08 T No, don't look at the blackboard. Don't look at the blackboard. Just look at us.

09 S4 singular countable nouns change plural, add $s[\ldots]$ [S4 finally moves his eyes away from the blackboard and faces the class talking, but shortly gets stuck and turns back again reading from the blackboard. Ss laugh and laugh.]

$10 \mathrm{~T}$ Now don't look at the blackboard.

11 S4 then with the ones without s [...] [ignoring T's insistence, S4 continues to read from the blackboard.]

This episode highlights the constraints T3 imposed around activities in which students were ostensibly meant to be developing autonomy. The apparent handover of control in Turn 01 is prefaced 
with the instruction "you'd better tell us without looking at the blackboard", closely followed by "Do you understand?", which appears designed to elicit agreement to comply. The teacher follows with a series of further turns which reiterate this instruction; these interrupt the student's projected action no fewer than five times (Turns 03, 04, 06, 08, 10), beginning with two repetitions of the initial indirect instruction (Turn 03), followed by a series of imperatives in the following turns. Thus, while seeming to have released control for the student to present his answer, the teacher persistently interfered with the process, asserting firm control over the activity.

The post-lesson discussion reveals some of the LA-inhibiting dimensions of the teacher's thinking. Strikingly, she accounted for her instruction as an impromptu decision to "deliberately" make the task more demanding "for the purpose of taking the opportunity to develop students' attentive listening". The presenter was a student she described as "relatively slow and weak", and "it was an open lesson with many observers, so he might be quite nervous" (T3.L1.PLD); under such circumstances, T3's sudden insistence that he not refer to notes as planned seems to inexplicably undermine his public (open lesson) performance. T3 further described the student as "very peculiar and different from others", yet rather than accommodating this individuality, she said "I just wanted to straighten him out". Reflecting on this, she observed that "I might be a very dominant character and want to take control" and that her way of managing students might be a reflection of her "inner-heart thinking". This particular student gave her a "headache" and she admitted being preoccupied with "how to change him", yet despite trying "all sorts of ways, still [she] can't control him" (T3.L1.PLD). These and other reflections by the teacher, both on and within this episode, appear to expose a strong hidden desire to control the class and students, little awareness in catering for students' individuality, and suggest little genuine understanding of the nature of LA.

\section{Episode 3}

As a final illustration of LA-subverting behaviours in the presentation session, it is worth briefly mentioning how T3 closed this phase of the lesson. Six groups had written their rules on the board and were scheduled to speak. However, T3 abruptly terminated the activity after the third, while the fourth group stood awaiting their turn (T3.L1.O). To terminate a previously understood sequence of turns in this way appears a powerful assertion of control$^{2}$. In doing so, the opportunity for learnerbased activity was sacrificed - and the learner's pace of learning ignored - to accommodate the teacher's agenda, far from the ideal of "a negotiated agenda" (Trebbi, 2003, p. 235).

\section{General beliefs \& summary}

It is frequently the case that teacher beliefs and practices diverge (Gross, 2015) and typically this in itself would barely warrant discussion. However, the present case seems remarkably divergent. T3 stated her basic understanding of LA as involving students taking an active role in their learning: "Autonomous learning is to change students from being passive to being active (zhu dong). Let them be the agents (zhu ti) in class, participating actively rather than just listening to teachers passively. [Autonomy] is the inner drive (dong li) [for someone] to act on his own (zi ji)" (T3.I). She claimed strong belief in students' capabilities for independent learning and a determination to release control to students with no concern about classroom management issues: "Students are very smart. I believe they can solve many problems by themselves. I love to get students working busily in groups. I let them go in their own way. I don't mind the class looking chaotic, as long as students are actively engaged" (T3.I). As should be evident, these professed beliefs stand in stark contrast to those actually enacted in the episodes discussed above.

\footnotetext{
${ }^{2}$ By way of comparison, it seems inconceivable that a student could enact such a termination.
} 
To briefly summarise, then, we have presented a case in which the teacher claimed both an affinity for LA and was lauded within the school for her LA-promoting practice, and yet analysis of her practices indicates they were in strong opposition to LA. Rather than building an argument based on cherrypicked incidents, we have focused on episodes drawn from a sequence of actions within a single (showcase) lesson. The episodes here illustrate respectively (1) a sequence involving a very tightly controlled format with very little opportunity for learner-initiated activity and little use of English, (2) a sequence in which the handover of control to a student occurs only with the imposition of an arbitrary constraint and persistent interruptions to reinforce it, and (3) a brief description of the abrupt termination of the lesson phase, representing an assertion of control preventing half of the planned student contributions.

\section{T2: "I know the core ideas and embed them into my teaching. ... Students did well, often much beyond my expectations.”}

Among the nine teachers, $\mathrm{T} 2$ appeared to have the most consistent and deeply-embedded approaches to promoting autonomous learning, as partially suggested within the overview of teacher practices in Table 3 (Appendix 3). She provided a wide range of opportunities for active student involvement, appropriately facilitated student-controlled activities, and attended to students' needs for both free authentic communication and cultivation of autonomous study skills. She spoke eloquently in providing sound rationales for most of her LA-related practices, expressing trust in learners' potential to be autonomous, and demonstrating an astute understanding of the nature of LA.

\section{Episode 1}

The following episode is taken from the opening minutes of T2's first open lesson of the semester, in which a student is selected to give a pre-lesson presentation involving the retelling of a learnt text. This selection process was jointly conducted with students through T2's question prompts and achieved entirely in English.

Observation Extract T2.L1.E1

[Class commences. Students stand and greetings are exchanged].

$01 \mathrm{~T}$ Just now a few of you said Group 1 and Group 6, only few of them recited the text. Now, I just wanna choose one. Group 1 and 6, which one?

02 Ss One, one $<$ six, six, six $>$. [ss yelling different numbers]

$03 \mathrm{~T} \quad$ Okay, Group 6. Number ---

04 Ss Three three three $<$ four four four four $>$. [ss yelling different numbers]

$05 \mathrm{~T} \quad[\mathrm{xxx}]$ has done $[\mathrm{xxx}][\mathrm{T}$ bends to check with a student in the front.]

06 Ss Four four four [ss yelling]

07 T Okay Four. Number 4. Welcome. [ss clap hands; a boy student comes to the front.] Which passage?

08 Ss $\quad[\mathrm{xxx}]$ [ss giving T suggestions]

$09 \mathrm{~T}$ Ok the newest.

10 Ss $\quad[\mathrm{xxx}][$ ss yelling] 
$11 \mathrm{~T}$ Oh Jenny Ian. Do you remember? [T giving prompt to start] Do you remember Jenny Ian ---

12 Ss $[\mathrm{xxx}][$ ss chorus the text]

$13 \quad \mathrm{~T} \quad$ Shiiiiiii [ $\mathrm{T}$ focuses attention on the presenter]

14 S1 Do you remember [...] [the boy recites the text]

A turn by turn analysis of this brief episode proves revealing. Prior to the extract presented here, there was noise and chatter among students before the class stood and greeted the arriving teacher. As revealed in Turn 01, T2 had evidently gathered from the student chatter that Groups 1 and 6 were due an opportunity to present, and in Turn 01 she narrows the selection options to these two. Students respond in Turn 02, with calls for Group 6 being louder and more numerous, to which T2 concurs. In Turn 4, the students then call out various student numbers, of which Three and Four are the most perceptively prominent. At this point (Turn 05 ), partially drowned out by voices, T2 points out that one of the candidates (perhaps Student 3) has presented previously. Calls for Student 4 then become overwhelming and $\mathrm{T} 2$ calls him to the front. This is mirrored elsewhere with the teacher acceding to the most popular nomination for a text to read. At this micro-level of decision-making, we see a degree to which the teacher invites students to individually contribute suggestions, with the most popular choices likely to be adopted. In this way, although undoubtedly wielding the real power, the teacher ostensibly acts as the chair, generally approving the options arrived at by student consensus, and - crucially - providing a rationale for discounting some of the proposed options (Lines 01 and 05). The result is shared control in selecting the presenter and the text.

This aligned with the beliefs T2 articulated in the post-lesson discussion, where she spoke of valuing learner empowerment and trusting in them to take opportunities. In delegating some decision-making, she "transferred part of [her] teacher authority to students", believing they would "exercise the given power in a desirably positive way". She added: "I trust them; they are positive and upright; and they choose the most difficult section to challenge their fellow classmates" (T2.L1.PLD).

The ensuing activity involved the presenter retelling the selected story, not word-for-word, but with "flexible changes" to "practise using the learnt language in the text" (T2.L1.PLD), thereby allowing for the exercise of agency. As audience members, students were asked to "listen attentively, compare with what's in their own memory, and spot any mistakes in the reciting and suggest corrections" (T2.L1.PLD), thereby allowing for collaborative control (peer monitoring) over learning outcomes. The task was achieved entirely in English and for both the presenter and audience promoted a degree of autonomous language use. In the post-lesson discussion, T2 emphasised the communicative function of language embodied in the design of the presentation task and, for the audience task, she professed to focus more on the process of self- and peer-checking than on the actual errors, stressing the opportunity to develop study skills: "learn to be a good listener", by way of "showing respect to the speaker first of all, and keep one's thinking actively involved" (T2.L1.PLD).

\section{Episode 2}

Another approach T2 adopted was collaborative group learning. This was employed in both the observed lessons, with the second (more comprehensive use) illustrated here. The lesson objective was "to use the simple past tense to talk about the past" (T2.L2.Worksheet). The lesson was composed of the following phases:

Step 1. warm-up chat

Step 2. autonomous ( $z i z h u)$ learning: checking past tense verbs and time expressions

Step 3. talking in groups and with the teacher about "My life two years ago"

Step 4. individual writing and editing

Step 5. peer sharing and editing 
Step 6. reading (T2's composition)

Step 7. redrafting their composition (T2.L2.O; T2.L2.Worksheet).

T2 led the warm-up chat in Step 1, with the topic flowing from that day's weather to the previous day's, and then to an earlier school event. In Step 2 (autonomous [zi zhu] learning), students first worked silently on three worksheet tasks focusing on verb forms and past time expressions, before checking their answers against a key. In Step 3, students used the time expressions, talking firstly in groups about their past experiences, and then with $\mathrm{T} 2$ about their primary school experiences (T2.L2.O). As preparation for writing, they individually wrote key sentences about these experiences before the teacher nominated some to read theirs aloud. She then elicited ideas based on prompts from a writing outline presented in PowerPoint, such as "where/what you studied, how you got to school, happy or not" (T2.L2.PPT). In Step 4, the actual writing session, students were instructed to (re)organise their thinking, write their own draft and then self-edit. During all writing stages, the teacher circulated around the classroom but did not interact with students. In Step 5, students swapped their writing with a group member to "learn the strengths from others and help them identify problems, and then note down good sentences from their writings" (T2.L2.Worksheet). With time up, $\mathrm{T} 2$ assigned her own sample writing as reading homework (Step 6), to be followed by students redrafting their own work (Step 7) (T2.L2.O).

Among LA-promoting features, the lesson contained a series of independent and collaborative learning opportunities, in which students were taking or sharing control and exercising agency. The former included opportunities for self-trial (e.g. individually working on verbs, sentence writing, extended writing), monitoring/assessing (independently checking with answer keys), reflection (selfediting) and reconstruction (reorganising and rewriting). Agency was exercised in the two groupwork sessions (talking in groups; peer-reviewing first drafts). When control shifted to students, T2 provided guidance and support for content/meaning (e.g. warm-up chat about the past; targeted writing topic) and language (lexical, syntactic, and discoursal levels). Opportunities for autonomous language use were evident in the warm-up chat, which invited authentic communication from students. Evidence of student empowerment may be detected in the teacher performing the same writing task as a sample, revealing something of her own personal history, while eschewing more grammatically and stylistically complex language (which would have reinforced her status as the expert language user) in favour of level-appropriate language to which the students could reasonably aspire.

In the post-lesson discussion and interview, T2 articulated largely sound rationalisations for Steps 1-7. She explained her scaffolding actions in Steps One to Three as being "step-by-step building-up to prepare students for the subsequent first draft writing" (T2.L2.PLD), with both the informal chat at the beginning and her own story being planned. In both, she had the dual purposes of "catching every possible opportunity to have real-life communication" and "putting [herself] among students", insisting that "the primary purpose to learn a language is for communication rather than examination" and "good rapport with students inspires and motivates them and facilitates their learning” (T2.L2.PLD).

She further emphasised self-study and discussed various self-based activities she that she had used in her own language learning. She stated that she found self-study "the most efficient way of learning", in that it is "self-reliant" and hence "unconditional", and readily "conducted anywhere anytime". Subsequently, she emphasised the benefits of group work, stating that "discussion clarifies one's own thinking and stimulates and inspires each other's", and that "group work increases participation" through offering different roles to more and less skilled language users (T2.L2.PLD). She also stressed the value of cognitive processing: "Whether new knowledge is constructed autonomously (zi zhu) or collaboratively ..., the very last step must be self-internalisation. Only through a self-digestion 
or reflection, can what you have learned become genuinely your own, and can you then use it freely" (T2.I).

In relation to peer-marking and editing, $\mathrm{T} 2$ commented that "it did not matter much what mark they gave to each other; but to make a judgement, they needed to think critically" (T2. L2.PLD), a view of critical thinking aligned with the LA literature. On the use of performance points, as promoted by the director, she said "when using such points the teacher must have an genuine intention to give control to students" and that in her "experience as long as [she] seriously gave, [her] students seriously took the power to judge [other students' work]" (T2.L2.PLD, bold indicating emphasis).

\section{Episode 3}

It is, however, also worth briefly acknowledging a practice observed on one occasion which appeared to undermine T2's control handover. As students planned and wrote their first drafts, T2 persisted in talking, providing further instructions or reminders such as "don't haste to write; reorganise your thinking". This deviated from her stated beliefs and is a practice she had been critical of in another teacher's open lesson (OD1). When asked about it in the interview, she expressed surprise and was evidently unconscious of doing so.

General beliefs \& summary

Overall, T2 demonstrated deep understanding of principles of LA. She described autonomy as " $a$ capacity to act independently [du li], analyse and solve problems by oneself [zi ji], with or without external help available" and "an inner strength that keeps people calm and confident in all situations" (T2.I). She stressed that "autonomy influences one's way of saying, doing, and thinking, that is, character forming" and that "it is something hard to describe, but comprehensively good for one's wellbeing" (T2.I).

While space constraints prevent detailed presentation of other relevant findings, the preceding episodes should provide ample evidence that $\mathrm{T} 2$ shifted or shared control with students in ways that promote a degree of LA in distinct contrast to the practices of T3. The episodes discussed here include (1) close analysis of a sequence of talk revealing LA-conducive actions at the micro-level of teacherstudent interaction over selecting materials and presenters: $\mathrm{T} 2$ responds genuinely to the will of the class and the ensuing activity involves autonomous language use and peer feedback; and (2) analysis of a near lesson-length sequence of activities involving multiple dimensions of LA-promoting practice, including independent and collaborative work, authentic language use, peer feedback, and opportunities for exploration and reflection. Conversely, a third episode also reveals evidence of T3's behaviour placing unconscious constraints on LA.

\section{Discussion \& implications}

\section{Contribution of mixed methods with observation data}

The present findings investigate language teachers' beliefs and practices relating to the promotion of learner autonomy in the context of Chinese curricular reform, and in so doing respond to Borg and Alshumaimeri's (2019) call for the use of empirical evidence and mixed-methods. The contribution lies particularly in the utilisation of empirical data from multiple sources to examine two contrasting case studies, from which detailed pictures emerge of how the two teachers facilitated (or inhibited) learner control and how they accounted for their practices in both their reflections on specific actions and their more general beliefs about LA. In relation to their practices, the analyses reveal ways in which control was withheld or released at various levels of classroom activity, from micro-level moment-by-moment decision-making to larger sequences of organised activity. In relation to their beliefs, interviews and post-lesson discussions elicited teachers' perceptions of their practices and other claims about their underlying orientation to LA. 


\section{Complexity and delicacy in control shift}

Among all nine teachers, evidence of control shift was identified in most lessons but varied in degree and manner from teacher to teacher and from lesson to lesson, representing a spectrum of control release (Candy, 1991). Teachers 2 and 3 represent contrasting positions along this spectrum. T2 was observed to offer the most genuine and abundant opportunities for student control, with these practices aligning with her beliefs about LA. Control shift was both planned (at the levels of overall lesson and task design) and responsive (at the level of moment-by-moment decision-making). By contrast, T3 maintained tight command over events, which stood in stark contrast to her strongly professed support for LA principles ${ }^{5}$. When seemingly releasing control, she promptly reclaimed it (e.g. the 'tug-of-war' episode) in what amounts to false or pseudo control release (Candy, 1991; Dam, 2011). In such ways, ostensive LA represents a delicate state in which student decision-making is tightly constrained and the teacher retains a conspicuous, ever-present authority to intervene at whim.

An important issue to emerge from these findings is evidence of what we label masked teacher control within ostensibly student-led activities. In such cases, deeply-rooted teacher control is merely shrouded in a few trappings of LA, whether to manage audience impressions (as may happen under observation) or to preserve the comfort and familiarity of command (as may also be the case here). For instance, in T3's presentations and peer-comment sessions, students had been trained to follow highly-uniform procedures and signals, with this rigid format presumably instilled in previous lessons. Thus, while the near absence of teacher-talk outwardly resembles control shift, the weight of the

\footnotetext{
${ }^{3}$ see also Author1 (2017b) for discussion of the beliefs and practices of school management.

${ }^{4}$ T2 was the teacher with the most effective and deeply embedded LA practices and beliefs; among those who professed LA-aligned beliefs, T3's practices were less LA-facilitative.

${ }^{5}$ It is worth reiterating here that T3's practices were far from the least LA-aligned, with Teachers 6, 7 and 9 all demonstrating more traditional teacher-centred practices and in some case expressing LA-resistant beliefs.
} 
teacher's invisible control in fact suggests an even greater than usual underlying dominance. In such cases, apparent learner control is a delicate veneer over deeper structures of teacher control.

This spectrum of practices can be plausibly traced to aspects of the participants' beliefs, understanding and identity within the context of Chinese educational reform. Overall, T2's practices had the clearest alignment with her beliefs: her displays of trust in learner capacity for autonomy mirrored her expressed understanding of the concept of LA, her greater awareness of related pedagogy, and sounder rationalisation for her practices. As exemplified above, she articulated these in ways that appeared relatively novel, suggesting she was verbalising an internalised understanding rather than merely reciting platitudes. A key factor appears to be her confidence and autonomy as a teacher: she occupied a leadership role at the school, was held in high esteem by staff and students, was the most proficient in English, and had previously taught at a university. It seems likely that her professional confidence made it easier to shift control to learners, knowing that she could comfortably manage the situation. It may also be that she had a personal affinity towards LA: she spoke of being an autonomous learner herself, and of autonomy and independent problem-solving being among her family's values.

The misalignment in T3's practices and stated beliefs can be similarly be traced to corresponding factors. Despite her expressed enthusiasm towards LA and a general understanding linking it to learner-centredness, her articulation was much less convincing, largely appealing to familiar dictums such as "learning from mistakes", "active rather than passive learning" and "students are capable". These suggest a more superficial understanding. Our impression is that they were newly adopted beliefs (probably prompted by the school-wide LA initiative) that T3 had not yet reconciled with her established practices and implicit understandings ${ }^{6}$. Her own educational experience would have been very much teacher-centred, likely forming the core of her understanding to which some trimmings of LA were overlaid. Also worth noting is the likely role for T3's professional identity in the enactment of her beliefs: her recent appointment to the school represented a significant career promotion and she was undoubtedly striving to make a strong impression. Somewhat lacking confidence in herself and her students, she kept to her tightly organised lesson plan, seemingly a safe option in front of a dozen observers including the director.

Beyond LA, the present findings suggest wider implications within contexts of educational reform and innovation. Recognising the need for shifts in thought and practice, the school had put in place a seemingly comprehensive PD system based particularly around modelling teaching approaches, and post-lesson discussions of open lessons. However, there was limited ongoing discussion and structured reflection on the underlying principles. Without this deeper understanding, while T3 was still able to follow the steps provided in the teaching models (recall that she was put forward by the department as a model of best practice), closer examination reveals that her moment-by-moment decision making was counterproductive, particularly at the micro-level of shifting control. As Watanabe (2017) argues in her expansion approach to professional development, true development involves not only acquiring new techniques, but engaging deeply with one's understandings around practice, theory, identity, students, and context. In short, it seems that successful educational reform is likely to require substantial support for development in teacher cognition.

\footnotetext{
${ }^{6}$ In such cases, the most effective professional development may be reflective practice that focuses on the alignment between beliefs and practice (Farrell \& Ives, 2015); T3's post-lesson reflections already included the realisation that "maybe, unconsciously, I'm quite dominant", which suggests an impetus for development.
} 
Complimenting the present study of control shift, it would be worthwhile for future empirical studies to explore teachers' practice and cognition in relation to supporting learners' to actually accept or take control.

\section{Feasibility of $L A$ in conventional non-Western classroom settings}

As outlined in the literature review, a constellation of factors is required to effectively support LA (e.g. learner involvement, authentic language use, awareness raising) and this raises the crucial question of how feasible LA is within a given context. Cortazzi and Jin's (1996) influential work on cultures of learning has further clarified that pedagogical practices that are successful in one context may lack transferability to another. In this vein, it has been remarked that aspects of Chinese educational culture present obstacles to the implementation of LA (Ho \& Crookall, 1995), and even that LA may be "inappropriate" within some social and political contexts (as reported by Little, 2007a, p. 11) 7 .

However, the present findings demonstrate that LA can indeed be fostered in conventional classrooms in ways consistent with how it has been operationalised previously (e.g. Chang, 2007; Chen \& Hird, 2006; Dam, 1995). This includes student involvement in selecting topics and materials, individual collaborative inquiry, communicative language use, self/peer-monitoring, and peer feedback. Control shift was further identified in areas such as classroom management, for example stronger students assisting teachers with classroom interactions or managing student records.

Assuming institutional support, the crucial factor in the feasibility of LA thus appears to be the moment-by-moment enacted beliefs and other actions of individual teachers. The contrasting cases of $\mathrm{T} 2$ and T3 reveal striking divergences in conducting similar tasks in similar contexts, which either facilitate or impede LA. Questions of the feasibility of LA should not, therefore, be settled a priori with reference to generalities such as culture and setting, but be deduced from the beliefs and practices of the teachers in whose hands it is entrusted.

One final point, however, is that even for T2, learner involvement was not consistent over the semester and did not manifest at the macro level of overall course design; rather, it was identifiable within specific activities. For example, learner selection of topics and materials was only witnessed in the pre-lesson presentations. Similarly, peer-evaluation/assessment was confined to specific points rather than longitudinal progress and mainly in the fairly simple manner of suggesting performance scores. Other aspects of LA that feature in the literature were not evidenced at all, such as student involvement in defining needs, objectives, progression or teaching methods (Borg \& Al-Busaidi, 2012; Reinders, 2010). Similar findings are reported elsewhere and are often attributed to institutional constraints such as prescribed curriculums (e.g. Borg \& Al-Busaidi, 2012; Wang \& Wang, 2016). With this in mind, the present findings can be interpreted in a promising light, as some teachers exercised their professional autonomy in identifying and creating opportunities for learner autonomy. Key to this is the teacher's genuine understanding and unshakeable trust in students' capacity for autonomy.

\section{References}

Barnard, R., \& Li, J. (Eds.). (2016). Language learner autonomy: Teachers' beliefs and

\footnotetext{
${ }^{7}$ Note that, like us, Little (2007a) challenges this position.
} 
practices in Asian contexts. IDP Publications Asia.

Benson, P. (2001). Teaching and researching autonomy in language learning. Longman.

Benson, P. (2003). Learner autonomy in the classroom. In D. Nunan (Ed.), Practical English language teaching (pp. 289-308). McGraw Hill.

Benson, P. (2011). Teaching and researching autonomy (2nd ed.). Pearson.

Borg, S. (2003). Teacher cognition in language teaching: A review of research on what language teachers think, know, believe, and do. Language Teaching, 36(2), 81-109. https:/doi.org/10.1017/S0261444803001903

Borg, S. (2018). Teachers' beliefs and classroom practices. In P. Garrett, \& J. Cots (Eds.), The Routledge handbook of language awareness (pp. 75-91). Routledge.

Borg, S. (2019). Language teacher cognition: Perspectives and debates. In X. Gao (Ed.) Second handbook of English language teaching (pp. 1149-1170). Springer.

Borg, S., \& Al-Busaidi, S. (2012). Learner autonomy: English language teachers' beliefs and practices. The British Council.

Borg, S., \& Alshumaimeri, Y. (2019). Language learner autonomy in a tertiary context:

Teachers' beliefs and practices. Language Teaching Research, 23(1), 9-38. https://doi.org/10.1177/1362168817725759

Camilleri, G. (1999). Learner autonomy: The teachers'views. Retrieved from http://archive.ecml.at/documents/pubCamilleriG_E.pdf

Candy, P. C. (1991). Self-direction for lifelong learning: A comprehensive guide to theory and practice. Jossey-Bass.

Chang, L. Y.-H. (2007). The influences of group processes on learners' autonomous beliefs and behaviors. System, 35(3), 322-337. https:/doi.org/10.1016/j.system.2007.03.001

Charmaz, K. (2006). Constructing grounded theory: A practical guide through qualitative analysis. Sage.

Chen, R.-Y., \& Hird, B. (2006). Group work in the EFL classroom in China: A closer look. RELC Journal, 37(1), 91-103. https:/doi.org/10.1177/0033688206063476

China MoE (2001a). 基础教育课程改革纲要(试行) [National curriculum reform for Basic Education (trial)]. Retrieved from http://www.gov.cn/gongbao/content/2002/content_61386.htm

Cortazzi, M., \& Jin, L. (1996). English teaching and learning in China. Language Teaching, 29(2), 61-80. https://doi.org/10.1017/S0261444800008351 
Creswell, J. W., \& Plano Clark, V. L. (2011). Designing and conducting mixed methods research (2nd ed.). Sage.

Dam, L. (1995). Learner autonomy 3: From theory to classroom practice. Authentik.

Dam, L. (2011). Developing learner autonomy with school kids: Principles, practices, results. In D. Gardner (Ed.), Fostering autonomy in language learning (pp. 47-58). Zirve University.

Farrell, T. S. C. and Ives, J. (2015). Exploring teacher beliefs and classroom practices through reflective practice: A case study. Language Teaching Research, 19 (5), 594610. https://doi.org/10.1177/1362168814541722

Feryok, A. (2010). Language teacher cognitions: Complex dynamic systems? System, 38(2), 272-279. https://doi.org/10.1016/j.system.2010.02.001

Glaser, B. G., \& Strauss, A. L. (1967). The discovery of grounded theory: Strategies for qualitative research. Aldine Publishing Company.

Gross, R. (2015). Psychology: The science of mind and behaviour (7th ed.). Hodder Education.

Harding, J. (2013). Qualitative data analysis from start to finish. Sage.

Ho, J., \& Crookall, D. (1995). Breaking with Chinese cultural traditions: Learner autonomy in English language teaching. System, 23(2), 235-243. https://doi.org/10.1016/0346251X(95)00011-8

Holec, H. (1981). Autonomy and foreign language learning. Pergamon.

Huang, J., \& Benson, P. (2013). Autonomy agency and identity in foreign and second language education. Chinese Journal of Applied Linguistics, 36(1), 7-28. https://doi.org/10.1515/cjal-2013-0002

Jin, L., \& Cortazzi, M. (2006). Changing practices in Chinese cultures of learning. Language, Culture and Curriculum, 19(1), 5-20. https://doi.org/10.1080/07908310608668751

Kohonen, V. (2010). Autonomy, agency and community in FL education: Developing sitebased understanding through a university and school partnership. In B. O'Rourke \& L. Carson (Eds.), Language learner autonomy: Policy, curriculum, classroom (pp. 3-28). Peter Lang.

Lee, S.H., Smith, D. and Sergueeva, K., 2016. What do students think about group work in business education? An investigation into the benefits, challenges, and student-suggested solutions. Journal of Education for Business, 91(7), pp. 380-386. https://doi.org/10.1080/08832323.2016.1237933

Little, D. (2007a). Introduction: Reconstructing learner and teacher autonomy in language education. In A. Barfield, S. H. L. Brown \& D. Little (Eds.), Reconstructing autonomy in 
language education: Inquiry and innovation (pp. 1-12). Palgrave Macmillan.

Little, D. (2007b). Language learner autonomy: Some fundamental considerations revisited. Innovation in Language Learning and Teaching, 1(1), 14-29. https://doi.org/10.2167/illt040.0

Martinez, H. (2008). The subjective theories of student teachers: Implications for teacher education and research on learner autonomy. In T. E. Lamb \& H. Reinders (Eds.), Learner and teacher autonomy: Concepts, realities, and responses (pp. 103-124). John Benjamins.

Nunan, D. (1997). Designing and adapting materials to encourage learner autonomy. In P. Benson \& P. Voller (Eds.), Autonomy and independence in language learning (pp. 192203). Longman.

Peterson, M. (2012). EFL learner collaborative interaction in Second Life. RECALL, 24(1), 20-39. https://doi.org/10.1017/s0958344011000279

Reinders, H. (2010). Towards a classroom pedagogy for learner autonomy: A framework of independent language learning skills. Australian Journal of Teacher Education, 35(5), 40-55. https://doi.org/10.14221/ajte.2010v35n5.4

Robson, C. (2002). Real world research: A resource for social scientists and practitionerresearchers. Blackwell.

Seidel, J. V. (1998). Qualitative data analysis. http://www.qualisresearch.com/qda paper.htm

Shu, D.-F. (2004). 外语教学改革: 问题与对策/ELT in China: Problems and suggested solutions. Shanghai Foreign Language Education Press.

Shu, D.-F., \& Hua, W.-F. (2009). 中国外语教学理论研究六十年:回顾与展望 [Foreign language teaching theories in China in the last 60 years: Reviews and Prospects]. 外语教 学/ Foreign Language Education, 30(6), 37-44.

Storch, N. (2001). How collaborative is pair work? ESL tertiary students composing in pairs. Language Teaching Research, 5(1), 29-53. https://doi.org/10.1191/136216801666650977

Strauss, A. L. (1987). Qualitative analysis for social scientists. Cambridge University Press.

Trebbi, T. (2003). Curriculum development and learner autonomy in the foreign language classroom: Constraints and possibilities. In D. Little, J. Ridley \& E. Ushioda (Eds.), Learner autonomy in the foreign language classroom: Teacher, learner, curriculum and assessment (pp. 166-184). Authentik.

Voller, P. (1997). Does the teacher have a role in autonomous learning? In P. Benson \& P. Voller (Eds.), Autonomy and independence in language learning (pp. 98-113). Longman. 
Wang, Q. \& Ma, X. (2009). Educating for learner-centredness in Chinese pre-service teacher education. Innovation in Language Learning and Teaching, 3(3), 239-253. https://doi.org/10.1080/17501220903404475

Wang, Y., \& Wang, M.-X. (2016). Developing learner autonomy: Chinese university EFL teachers' perceptions and practices. In R. Barnard \& J. Li (Eds.), Language learner autonomy: Teachers' beliefs and practices in Asian contexts (pp. 23-42). IDP Publications Asia.

Watanabe, A. (2017). Reflective practice as professional development: Experiences of teachers of English in Japan. Multilingual Matters.

Woods, D., \& Çakır, H. (2011). Two dimensions of teacher knowledge: The case of communicative language teaching. System, 39(3), 381-390. https://doi.org/10.1016/j.system.2011.07.010

Xu, Y., \& Wong, H. (2011). School-based curriculum development in China. Chinese Education \& Society, 44(4), 44-63. doi:10.2753/ced1061-1932440403 


\section{Appendices}

Appendix 1 Table 1: Participant profiles

\begin{tabular}{|c|c|c|c|c|c|}
\hline $\mathrm{T}$ & G & Job titles & Quals & Ys & Previous working experience \\
\hline $\mathrm{T} 1$ & $\mathrm{~F}$ & $\begin{array}{l}\text { English T \& Head of } \\
\text { Department } \\
\text { (Years 6-9) }\end{array}$ & BA 2006 & 6 & $\begin{array}{l}\text { English teacher in a tertiary college } \\
(2006-2012)\end{array}$ \\
\hline $\mathrm{T} 2$ & $\mathrm{~F}$ & $\begin{array}{l}\text { English T \& English } \\
\text { Programme Manager } \\
\text { (Years 1-9) }\end{array}$ & BA 2001 & 11 & $\begin{array}{l}\text { English teacher in a tertiary college (2001-2004) } \\
\text { English teacher in another high school run by the } \\
\text { principal of the present school (2004-2011) }\end{array}$ \\
\hline T3 & $\mathrm{F}$ & $\begin{array}{l}\text { English T \& Year } 6 \\
\text { Dean }\end{array}$ & BA 2005 & 7 & $\begin{array}{l}\text { After-school English tutor in a private tutoring } \\
\text { provider } \\
(2005-2012)\end{array}$ \\
\hline $\mathrm{T} 4$ & $\mathrm{~F}$ & English T \& Form T & BA 2002 & 9 & $\begin{array}{l}\text { Bookstore assistant } \\
(2002-2003) \\
\text { High school English teacher } \\
(2003-2011)\end{array}$ \\
\hline T5 & $\mathrm{F}$ & English T & BA 2007 & 5 & Secondary school English teacher (2007-2009) \\
\hline T6 & $\mathrm{F}$ & English T \& Form T & BA 2000 & 12 & $\begin{array}{l}\text { University English teacher } \\
(2000-2007) \\
\text { English teacher and vice director at a private } \\
\text { tertiary institute } \\
(2007-2011)\end{array}$ \\
\hline $\mathrm{T} 7$ & M & English T \& Form $\mathrm{T}$ & $\begin{array}{l}\text { Two-year } \\
\text { Diploma } \\
1992\end{array}$ & 20 & $\begin{array}{l}\text { High school English teacher } \\
(1992-2002) \\
\text { Secondary school English teacher (2002-2012) }\end{array}$ \\
\hline T8 & M & $\begin{array}{l}\text { English T \& } \\
\text { International Affairs } \\
\text { Manager }\end{array}$ & BA 2007 & 5 & $\begin{array}{l}\text { English teacher, course adviser, and administrator } \\
\text { in a private institute of international study } \\
(2007-2012)\end{array}$ \\
\hline T9 & $\mathrm{F}$ & English T \& Form T & BA 2006 & 6 & $\begin{array}{l}\text { Secondary school English teacher } \\
(2006-2012)\end{array}$ \\
\hline
\end{tabular}

- $[$ Notes: $\mathrm{G}=$ Gender; Ys $=$ Years of teaching $]$

\section{T2 profile}

T2 occupied a complex position at the school in terms of her authority and reporting lines. She was part of the school's senior management team and had overall general charge of the English program and team, yet she also taught two classes (as did most other teachers) working under T1, the English group head. She was, then, in the unusual position within this school of being a senior manager largely carrying out the same day-day-day tasks as teachers (the bottom of the hierarchy) and reporting to $\mathrm{T} 1$.

In terms of her background, T2 had graduated in 2001 from a renowned university in a provincial capital city and then worked for three years in that university's English training department. Attracted by the principal's educational vision, she joined the first K12 school that he established in the south of China, thereby switching her career from tertiary to secondary level. Her decision to join the school 
Appendix 2 Table 2: Reported LA-oriented practices

\begin{tabular}{|c|c|c|}
\hline $\begin{array}{l}\text { Reported } \\
\text { practices }\end{array}$ & Examples & $\begin{array}{l}\text { Reported } \\
\text { by }\end{array}$ \\
\hline $\begin{array}{l}\text { Peer checking } \\
\text { of study } \\
\text { progress } \\
\text { (zhi shi guo } \\
\text { guan) }\end{array}$ & $\begin{array}{l}\text { "I asked students to pair up with a stable partner, and do pair-dictation } \\
\text { with vocabulary and check each other text-reciting. Once an item was } \\
\text { passed, they checked a box on the Progress Checking Worksheet (zhi } \\
\text { shi guo guan biao) on the wall, and accordingly they earn PFM Points } \\
\text { for their groups." (T4.I) }\end{array}$ & $\mathrm{T} 1, \mathrm{~T} 4$ \\
\hline $\begin{array}{l}\text { Intragroup } \\
\text { problem- } \\
\text { solving } \\
\text { (jiang xi ti) }\end{array}$ & $\begin{array}{l}\text { "When dealing with exercises (xi ti), I asked students first to compare } \\
\text { answers with each other in groups and then have a discussion against } \\
\text { the answer keys, focus on the wrong ones and try to figure out the } \\
\text { problems as many as they can. Then I asked each group to report to me } \\
\text { the unsorted items, and I only explained those commonly challenging } \\
\text { ones." (T1.I) }\end{array}$ & $\begin{array}{l}\text { T1, T3, } \\
\text { T4, T5, } \\
\text { T7, T9 }\end{array}$ \\
\hline $\begin{array}{l}\text { HoGs acting } \\
\text { as teacher } \\
\text { assistants }\end{array}$ & $\begin{array}{l}\text { "For many times, I didn't give students homework, but left it to the } \\
\text { HoGs. The next day they gave me a homework list showing who was } \\
\text { assigned to do what, and how well that was completed. They also } \\
\text { provided such caring feedback as "XXX has got such and such done, } \\
\text { this undone yet, but he is working on it". (T2.I) } \\
\text { "The HoGs assisted with some work which I used to do by myself, for } \\
\text { example, marking dictation (T7.I), taking turns to lead the morning } \\
\text { reading-aloud sessions (T8.I), and checking text-reciting” (T9.I). }\end{array}$ & $\begin{array}{l}\text { T2, T7, } \\
\text { T8, T9 }\end{array}$ \\
\hline
\end{tabular}

focused on is this study was driven mainly by a desire to relocate nearer to family, while still wanting "to follow the same principal".

\section{T3 profile}

T3 had a much more typical teacher role within the school, with no additional managerial responsibilities. Although of a similar age to many of the teachers, she was one of the latest to be recruited and her previous experience (outlined below) was outside the core education system. For these reasons, she may have initially been seen as having relatively low professional status and authority among her colleagues, and appeared keen to make a good impression through embracing the school's special character and suggested models of teaching; she did indeed appear to achieve this, as evidenced through her selection as the English department's model of good teaching practice.

In terms of background, T3 graduated with a degree in education in 2005 and had been working for 6 years in an after-school centre attached to Dulangkou, a school well-known across China for its student-centred learning. Such after-school centres open their doors at the conclusion of the normal school day and fill a dual role of extending student knowledge of the school curriculum and occupying students while parents are at work. While she was both well-recognised and well-paid in this position, she left to join the middle school for what she described as a combination of factors: the demanding and unusual working hours of the after-school work and lack of professional development opportunities, and her personal admiration of the principal's educational vision. 
Appendix 3 Table 3: Summary of teachers' LA-conducive practices

Choosing the best self-study learner
"From time to time, I set up a session for self-study, say 20 minutes. I divided it into two parts; first group members studying a given (part of) text individually, and then sharing the self-study learning outcomes within groups. They then chose one which demonstrated best self-study learning outcomes or skills, who would represent the group to present the learning outcomes again to the class." (T2.I)

Choosing the most collaborative group
"I used this with unit tests. I asked each group to create a test collectively before class, and then in class each group drew a peergroup-created test by lots. They then worked on it together as a group test, but I asked them to go individually, moving from the least to the most able student, each using a pen in a colour unique to him/her." (T2.I)

\begin{tabular}{|c|c|c|c|c|c|c|c|c|c|c|}
\hline & Students' involvement & T1 & $\mathbf{T} 2$ & T3 & T4 & T5 & T6 & . & T8 & T9 \\
\hline \multirow{9}{*}{$\begin{array}{l}\text { Pre-lesson } \\
\text { Presentation }\end{array}$} & Individual presenting & $\sqrt{ }$ & $\sqrt{ }$ & $\sqrt{ }$ & $\sqrt{ }$ & & $\sqrt{ }$ & & & \\
\hline & Team presenting & & & & & $\sqrt{ }$ & & & $\sqrt{ }$ & $\sqrt{ }$ \\
\hline & Deciding on presenters & & $\sqrt{ }$ & & $\sqrt{ }$ & & & & & \\
\hline & Deciding on materials & $\sqrt{ }$ & $\sqrt{ }$ & $\sqrt{ }$ & $\sqrt{ }$ & $\sqrt{ }$ & $\sqrt{ }$ & & $\sqrt{ }$ & $\sqrt{ }$ \\
\hline & Peer teaching vocabulary & $\sqrt{ }$ & & $\sqrt{ }$ & & & & & $\sqrt{ }$ & \\
\hline & $\begin{array}{l}\text { Ask \& answer about the } \\
\text { presentation }\end{array}$ & $\sqrt{ }$ & & $\sqrt{ }$ & & $\sqrt{ }$ & & & $\sqrt{ }$ & \\
\hline & $\begin{array}{l}\text { Peer error correction / critical } \\
\text { comments }\end{array}$ & $\sqrt{ }$ & $\sqrt{ }$ & $\sqrt{ }$ & & & & & & \\
\hline & $\begin{array}{l}\text { Evaluating presentation in PFM } \\
\text { Points }\end{array}$ & $\sqrt{ }$ & & & & & & & & $\sqrt{ }$ \\
\hline & Students' involvement & T1 & $\mathbf{T} 2$ & $T_{3}$ & T4 & T5 & T6 & $\mathbf{T 7}$ & T8 & T9 \\
\hline \multirow{8}{*}{$\begin{array}{l}\text { Collaborative } \\
\text { Group } \\
\text { Learning }\end{array}$} & Self-study & $\sqrt{ }$ & $\sqrt{ }$ & & & $\sqrt{1}$ & & $\sqrt{ }$ & $\sqrt{ }$ & \\
\hline & Group discussion & $\sqrt{ }$ & $\sqrt{ }$ & $\sqrt{ }$ & & $\sqrt{ }$ & & $\sqrt{ }$ & $\sqrt{ }$ & $\sqrt{ }$ \\
\hline & Presentation & $\sqrt{ }$ & $\sqrt{ }$ & $\sqrt{ }$ & $\sqrt{ }$ & $\sqrt{ }$ & $\sqrt{ }$ & $\sqrt{ }$ & $\sqrt{ }$ & $\sqrt{ }$ \\
\hline & Peer feedback & $\sqrt{ }$ & $\sqrt{ }$ & $\sqrt{ }$ & & & & & & \\
\hline & Evaluation & $\sqrt{ }$ & $\sqrt{ }$ & $\sqrt{ }$ & $\sqrt{ }$ & $\sqrt{ }$ & $\sqrt{ }$ & $\sqrt{ }$ & $\sqrt{ }$ & $\sqrt{ }$ \\
\hline & Internalisation & $\sqrt{ }$ & $\sqrt{ }$ & & & $\sqrt{ }$ & & & & \\
\hline & $\begin{array}{l}\text { Aspects beyond the promoted } \\
\text { model }\end{array}$ & & $\sqrt{ }$ & & & & & & & \\
\hline & Students' involvement & & & & T4 & T5 & T6 & & & \\
\hline
\end{tabular}




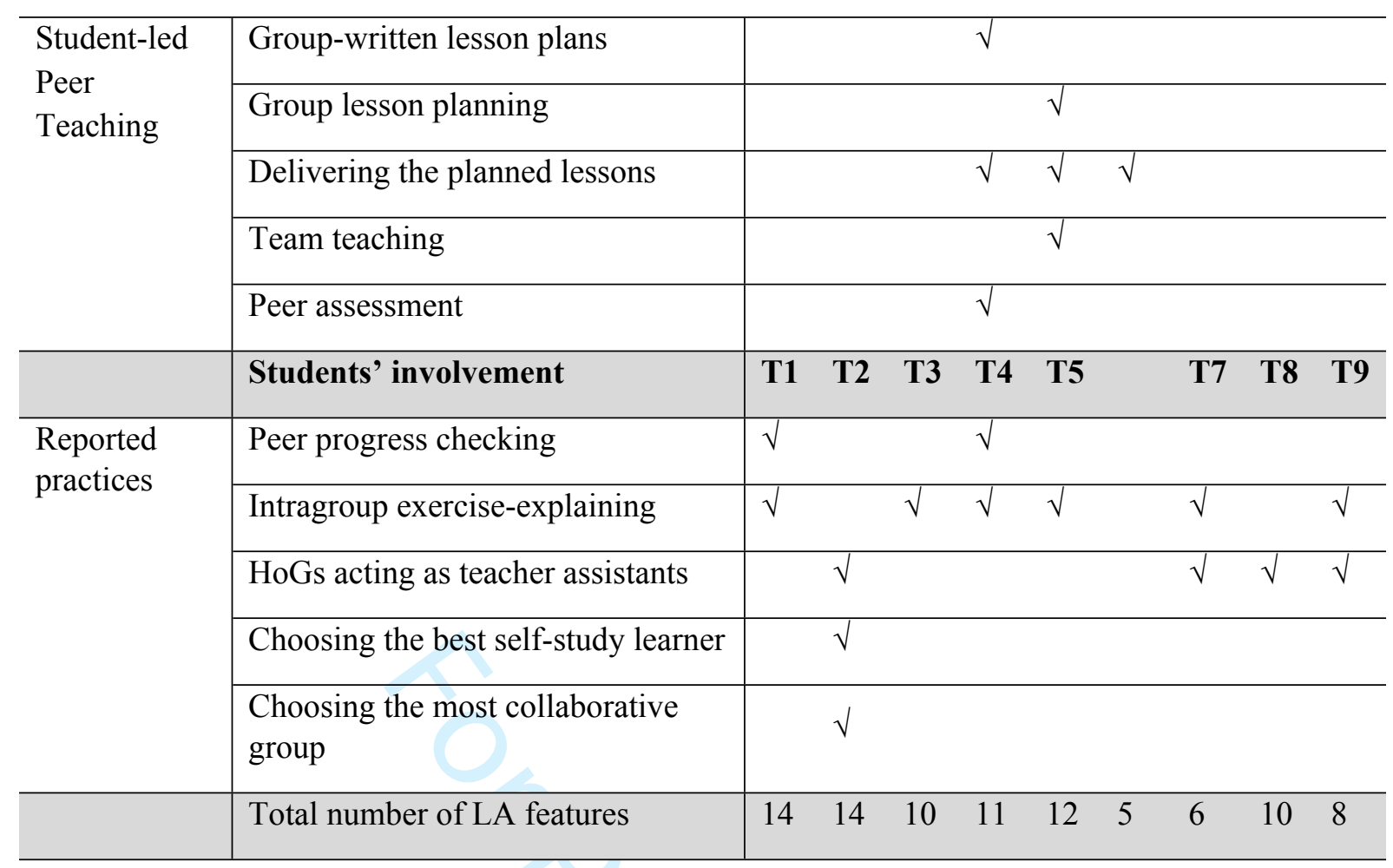

\section{Appendix 4 Extracts}

The two extracts from T3's classes reported in the main text are presented here with the original Chinese (English translations in italics).

T3.L1.E1: Group presentations on plural nouns

01 S1： 张组展示 er, er 一般的是 Group Zhang [a surname] is to present, er, er, the general ones are [T interrupted]

$02 \mathrm{~T}$ : 你展示的是什么内容? What is your presentation about?

03 S1: //类别构成一方法 // categories, forming methods

$04 \mathrm{~T}$ : 什么的类别和方法? categories, forming methods of what?

05 S1: III/名词 nouns

$06 \mathrm{~T}$ : 什么样的名词? What kind of nouns?

07 S1: er er er, 复数名词类别构成方法 categories, forming methods of plural nouns

$08 \mathrm{~T}$ : 不可数名词的复数吗? uncountable nouns' plural forms?

09 S1: 可数名词 plural nouns

10 T: Ok, go. 说清晰啊 make it clear.

11 S1: 一般的名词加 s, For general nouns, add s, book, books, bed, bed[s], 还有 and boy, boys .......然后, 以辅音字母 words with consonants IIIII

$12 \mathrm{~T}$ : 你可以看后边这个单词 You can look at the word following

13 S1: er er er 
$14 \mathrm{~T}$ : 它的这个规律都是从特殊的单词总结出来的, 你看 family 它是怎么变的吗? Its rule is summarised from special words, look at family, how is it changed? ok?

15 S1: / er er er // 加 add er, er er

16 T: Ok, don't be nervous. 不要紧张啊, 这个不会没有关系, Don't be nervous, you can't do it, it's ok. go on.

17 S1: 就这个? Just this one?

$18 \mathrm{~T}: \quad$ Yes $\uparrow$

19 S1: er family, families, oh, no

20 T: 这个知道了, 你说, we know this one, you say, ok

$21 \mathrm{~S} 1$ : 以辅音字母加 $\mathrm{y}$ 结尾的, 变 $\mathrm{y}$ 为 $\mathrm{i}$, 再加 $\mathrm{es,}$ consonant plus y ending, change y to i, then add es, family, families, party, parties.

22 T: $\quad$ OK.

23 S1：张组展示完毕。谢谢大家。That's all for Group Zhang's presentation. Thank you all.

24 Ss: 还有 And [xxxx]

25 S1: Oh,

$26 \mathrm{~T}$ : $[\mathrm{xxxx}]$ 咱们就不展示了, 时间关系, 咱们只看规则的, Due to limited time, let's leave that out, let's look at regular ones only Ok, go, come to the front, everybody.

27 S2: Er, er, 赵组补充 Group Zhao to add

28 T: Okgo

29 S2: ...还有不规则的, 比如 man 和 men...There are irregular ones, for example man and men.

30 T: Ok yes, go on

31 S3: 陈组补充, 字母加 $\mathrm{y}$ 结尾, 这个尾写错了 Group Chen to add, letter add y ending, this word 尾 [Chinese character for ending] is written wrong

32 T: Ok, yes [T and ss laugh] ...陈组补充完毕 That's all for Group Chen's adding. [S3 looked hesitant when going back]

33 T: Don't be nervous. 不要紧张, 没什么特别的, 放松 Don't be nervous, nothing special, relax.

Ok go on 继续 go on。陈组补充有效 Group Chen's addition was valid.

[T wrote "+2" to 陈组 Group Chen] 1251

T3.L1.E2: Tug-of-war between T3 and S4

$01 \mathrm{~T}$ Ok, now 岳组Group Yue, [...] Now 他们已经说过两遍了 they've presented for two times, now this time, $[\mathrm{xxx}]$, you'd better tell us without looking at the blackboard. Do you understand?

02 S4 Yes. [S4 was about to start].>

$03 \mathrm{~T}$ You'd better tell us without looking at the blackboard. Without, without looking at the blackboard [T using gestures to illustrate the idea not to look at the blackboard.]. You just look at us. Yes $\uparrow$ Ok, go.

[S4 turned to the blackboard and was to start.]

04 T Don't, don't look at the blackboard [T's voice raised sharply]. Look at us. Yes $\uparrow$ Ok. Look at us. 
05 S4 Er, er [S4, still looking at the blackboard, was starting to read.]

06 T No. Without. [T using gestures to illustrate the idea not to look at the blackboard; ss laugh.] 不要看 黑板 Don't look at the blackboard. Yes $\uparrow$ Ok. Go.

07 S4 岳组展示 Group Yue is to present [...][S4 ignores T's instruction and starts to read from blackboard.]

08 T No, don't look at the blackboard. Don't look at the blackboard. Just look at us.

09 S4 单数可数名词变复数是加s singular countable nouns change plural, add $s$ [...] [S4 finally moves his eyes away from the blackboard and faces the class talking, but shortly gets stuck and turns back again reading from the blackboard. Ss laugh and laugh.]

10 T Now don't look at the blackboard.

$11 \mathrm{~S} 4$ 然后复数不以s结尾的 [...] then with the ones without s [...] [ignoring T's insistence, S4 continues to read from the blackboard.]

Appendix 5 Tabulation 2: Analysis of major tasks

The following sample from the second main data tabulation illustrates how lessons were analysed in terms of the minute by minute activities that occurred in each class. Column 1 presents the timing of the activities by the minute; blank rows indicate a continuation of the activity. In this case, the middle and righthand columns represent the first and second lessons by T2. A very brief description of each activity type is listed (in enough detail for the observer-researcher to recall), alongside a precise timing of the onset of new actions to the nearest second (e.g. $0458=4$ minutes 38 seconds into the lesson).

The focus of this form of analysis was to identify the activity types, their timing, sequencing, the identity of the agent of the action, and a brief description of the task. This provided a helpful breakdown of lessons into phases. A slightly simplified version of this tabulation (Tabulation 1) provided a useful means of comparing the main features of the 22 lessons, from which the most common teaching approaches were identified.

\begin{tabular}{|l|l|l|}
\hline Mins & Teacher 2 - lesson 1 - Textbook unit: 'Free time activities' & Teacher 2 - lesson 2 - Textbook unit: none \\
\hline 0 & $\begin{array}{l}0019 \text { greetings } \\
0051 \text { Pre-lesson presentation }\end{array}$ & $\begin{array}{l}\text { music } \rightarrow \\
0042 \text { greetings }\end{array}$ \\
\hline 1. & & 0105 weather T/ss \\
\hline 2. & & 0328 school event_T/ss \\
\hline 3. & & 0433 DXG part 2_individual \\
\hline 4. & 0458 about the observers & \\
\hline 5. & 0520 lead-in T/ss & \\
\hline 6. & & 1102 check answer -- 1210 \\
\hline 7. & & 1250 time expressions \\
\hline 8. & & \\
\hline 9. & & \\
\hline 10. & & \\
\hline 11. & & \\
\hline 12. & & \\
\hline
\end{tabular}




\begin{tabular}{|c|c|c|}
\hline 13. & 1358 activity phrases & \\
\hline \multicolumn{3}{|l|}{14.} \\
\hline 15. & \multirow{2}{*}{$\begin{array}{l}1525 \text { what do u usually do } \\
\text { - SS 'Talk to yourself' } \\
\text { - } \quad \text { s demo monologue in the } 1 \text { st person } \\
\text { s retelling monologue in the 3rd person }\end{array}$} & 1510 sentences \\
\hline 16. & & $\begin{array}{l}1611 \text { life in [name of primary school] } \\
1623 \text { ss talk_group }\end{array}$ \\
\hline 17. & \multirow{7}{*}{ 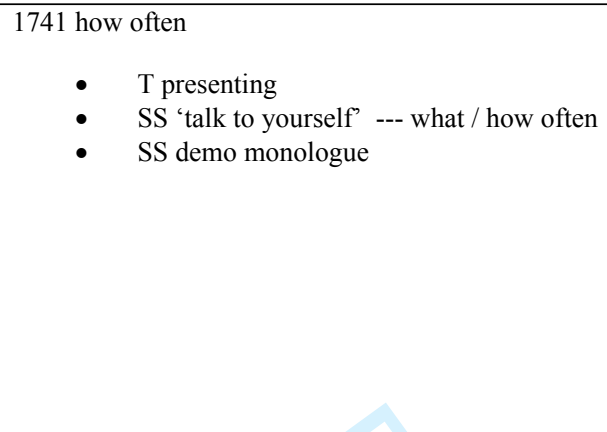 } & \\
\hline 18. & & \\
\hline 19. & & \\
\hline 20. & & \\
\hline 21. & & \\
\hline 22. & & \\
\hline 23. & & \\
\hline 24. & \multirow{12}{*}{$\begin{array}{l}2402 \text { p20 chart } \\
\text { - } \quad \text { ss individually work filling the chart } \\
\text { - ss 'talk to yourself' } \\
\text { - } \quad \text { ss pair work } \\
\text { ss pair work demo }\end{array}$} & \\
\hline 25. & & \\
\hline 26. & & \\
\hline 27. & & 2704 writing outline \\
\hline 28. & & 2833 ss rewrite \\
\hline 29. & & \\
\hline \multicolumn{2}{|l|}{30.} & \\
\hline \multicolumn{2}{|l|}{31.} & \\
\hline 32. & & 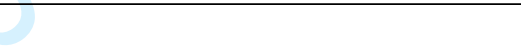 \\
\hline 33. & & \\
\hline 34. & & \\
\hline 35. & & \\
\hline 36. & \multirow{4}{*}{$\begin{array}{l}3627 \text { survey_group } \\
\text { - } \quad \text { ss group work } \\
\text { - } \quad \text { ss group report demo } \\
\quad \text { T / T-ss evaluating group demo }\end{array}$} & 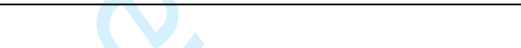 \\
\hline 37. & & 80 \\
\hline 38. & & 3857 self and peer review writing \\
\hline 39. & & \\
\hline $40+$ & Total time $4043+0641$ & 4006 homework $\rightarrow$ T sample writing $\rightarrow 4118$ \\
\hline
\end{tabular}

Key: BOC = beginning of class; DXG = Dao Xue Gao (lit. 'Guiding Learning Sheet'; worksheet); 
Appendix 6 Tabulation 3: Close look at learner involvement

The following sample is taken from the third main data tabulation used, illustrating at a broad level the main types of activity within each lesson in terms of the nature of learner involvement. The designation of 'main' activity was mostly a matter of the time allocated to certain activities, so excluded from the tabulation are a number of briefer (yet still important) activities such as the 'informal chat' that T2 opened her lesson with. Seven main activity types are listed (e.g. self-study; group/pair work); these were derived from the analysis and represent types that were typical within the 22 lessons.

The focus of this type of analysis was to identify broadly the types of learner involvement in activity, providing both a sketch of each individual teacher's main approaches and ready comparison across teachers. These provided important details leading into the closer of examination of individual episodes, as illustrated in the main body of the findings.

\begin{tabular}{|c|c|c|c|c|c|c|c|c|c|c|c|c|}
\hline $\mathrm{T}$ & Topic & T.L.E & Time & Task (what) & Task (how) & Self-study & $\begin{array}{l}\text { Group/pair } \\
\text { work }\end{array}$ & $\begin{array}{l}\text { Individual } \\
\text { presenting }\end{array}$ & $\begin{array}{l}\text { Group } \\
\text { presenting }\end{array}$ & $\begin{array}{l}\text { Add } \\
\text { Question } \\
\text { (peer } \\
\text { comments) }\end{array}$ & $\begin{array}{l}\text { Evaluating } \\
\text { (points to } \\
\text { group) }\end{array}$ & Internalise \\
\hline \multirow[t]{6}{*}{$\mathrm{T} 2$} & \multirow{4}{*}{$\begin{array}{l}\text { Yr } 7 \\
\text { Unit } 4 \\
\text { Free time } \\
\text { activities }\end{array}$} & 2.1 .1 & 1525 & What usually & Talk to yourself & $\sqrt{ }$ & & $\sqrt{ } \sqrt{S} 1 / \mathrm{S} 2$ & & & & \\
\hline & & 2.1 .2 & 1741 & what + how often & Talk to yourself & $\sqrt{ }$ & & $\sqrt{ }$ & & & & \\
\hline & & 2.1 .3 & 2402 & Free time activities & Fill in the chart & $\sqrt{\sqrt{ }}$ & $\sqrt{ }$ & & $\sqrt{ }$ & & & \\
\hline & & 2.1 .4 & 3627 & Free time activities & Make a survey & & $\sqrt{ }$ & $\sqrt{ }$ & & & $\mathrm{T} / \mathrm{SS} \sqrt{ }$ & \\
\hline & \multirow{2}{*}{$\begin{array}{l}\text { Yr } 7 \\
\text { Unit } 7 \\
\text { Weekend }\end{array}$} & 2.2 .1 & 0433 & Worksheet $1 / 2 / 3$ & Self-do /self-check & $\sqrt{\sqrt{ }}$ & & $\sqrt{ }$ & & & & $\sqrt{ }$ \\
\hline & & 2.2 .2 & 1623 & $\begin{array}{l}\text { Life in my primary } \\
\text { school }\end{array}$ & Write talk check & & $\sqrt{\sqrt{ }}$ & $\sqrt{ }$ & & & & $\sqrt{\sqrt{ } \sqrt{ } \sqrt{ }}$ \\
\hline \multirow[t]{8}{*}{$\mathrm{T} 3$} & \multirow{3}{*}{$\begin{array}{l}\text { Yr } 6 \\
\text { Unit } 5 \\
\text { Family }\end{array}$} & 3.1 .1 & 0520 & Grammar (-s/-es) & Present on bd & & $?$ & & $\sqrt{\sqrt{ }}$ & $\sqrt{ }$ & $\sqrt{ }$ & \\
\hline & & 3.1 .2 & 1928 & Photos & Talk & & & $\sqrt{ }$ & & $\sqrt{ }$ & & \\
\hline & & 3.1 .4 & 3730 & Dialogue & Gap-filling & $\sqrt{ }$ & $\mathrm{X}$ & & $\sqrt{\sqrt{ }}$ & $\mathrm{X}$ & & \\
\hline & \multirow{5}{*}{$\begin{array}{l}\text { Yr } 6 \\
\text { Unit } 8 \\
\text { Do you } \\
\text { have a } \\
\text { soccer } \\
\text { ball? }\end{array}$} & 3.2 .1 & 0651 & Grammar (Y/N ques) & Discuss & & $\sqrt{ }$ & $\sqrt{ }$ & & & & $\sqrt{1}$ \\
\hline & & 3.2 .2 & 1341 & Do you have... & Pair practice & & $\sqrt{ }$ & & $\sqrt{ }$ & $\sqrt{ }$ & & \\
\hline & & 3.2 .3 & 2301 & I/you don't have... & Pair practice & & $\sqrt{ }$ & & & & & \\
\hline & & 3.2 .4 & & 4 sentences & Change & & & $\sqrt{ }$ & & & & \\
\hline & & 3.2 .5 & 2706 & Grammar (Do/does) & Discuss & & $\sqrt{ }$ & $\sqrt{ }$ & & & & \\
\hline
\end{tabular}




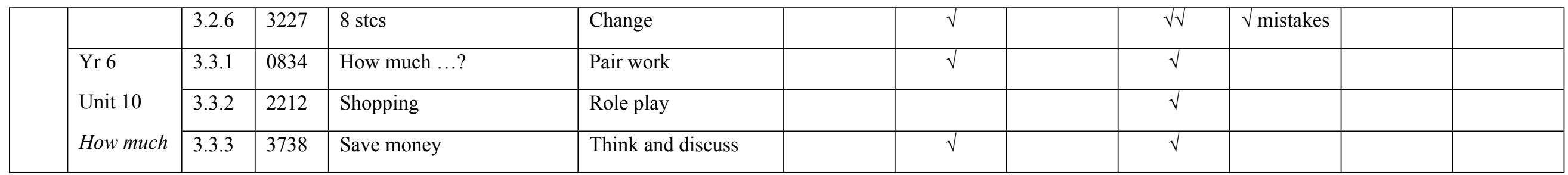

Key: Yr 6 = Year 6; TLE = Teacher, Lesson, Episode; bd = board;

Note: the question mark in row 7 relates to supposed before-class preparation, the details of which are unknown 


\title{
The complexity of control shift for learner autonomy: A mixed-method case study of Chinese EFL
} teachers' practice and cognition

\begin{abstract}
The promotion of language learner autonomy has been recognised as being beneficial in various domains, from linguistic achievement to personal growth. Key to the development of learner autonomy is shifting control from the teacher to the learner. While much has been written about the construct of learner control, there has been little close examination of the practices with which language teachers release their command. This paper reports on a study conducted in a Chinese private school intent on promoting learner autonomy, and explores ways in which teachers' practices facilitated or hindered control shift and their perceptions of these actions. From a study of nine teachers within one English department, two case studies are explored in depth through analysis of classroom practices, interviews and post-lesson discussions. While the feasibility of promoting learner autonomy in non-Western contexts has previously been questioned, the present findings highlight the opportunities available within routine tasks, while stressing the delicacy of these opportunities.
\end{abstract}

\section{Introduction}

Since the pioneering work of Holec (1981), language learner autonomy (LA) has been widely advocated, with perceived benefits going beyond linguistic and more general educational outcomes to include healthy personal and societal development (Benson, 2011). Given the core LA principle of learner control (Benson, 2001, 2011), the key action is shifting control from teachers to learners. However, this shift remains little explored in practice amidst a lack of empirical studies investigating teachers' understandings of the concept of LA (Borg \& Al-Busaidi, 2012) and a lack of "deeper qualitative analyses ... of how teachers conceptualize and promote [it]" (Borg \& Alshumaimeri, 2019, p. 29). This paper addresses this gap by reporting on a longitudinal case study in a Chinese school context.

China's Basic Education Curriculum Reform (China MoE, 2001) explicitly specifies LA as a key curricular goal, aiming to move classroom instruction from a routine of students' passively receiving information to one characterised by active learning and development through autonomous and collaborative inquiry. The Reform calls on teachers to create the conditions and opportunities for this to occur (China MoE, 2001). However, teacher education in this aspect has lagged behind, with most new teachers who join the profession lacking knowledge and skills in LA-oriented pedagogies (Wang \& Ma, 2009). In the meantime, LA initiatives have been promoted at schools throughout the country, with practitioners and administrators exploring approaches for student autonomy, collaboration and inquiry. As a result, by 2011, ten years into the Reform, intensive debate arose regarding the outcomes and effectiveness of the innovations, with views tending to be unfavourable and with teachers expressing frustration and irritation (Xu \& Wong, 2011).

Exploring both practice and cognition in a Chinese school context, this study aims to probe complexities in teachers' implementation of LA, their underlying rationales, and their understanding of the concept, with a view to identifying practical implications.

\section{Literature review}

\section{Learner autonomy and control shift}

Benson's (2001, p. 47) definition of LA in terms of control, specifically "the capacity to take control of one's own learning", provides for empirical observation of LA in the behaviour of teachers and learners (cf. 'learners' taking charge', Holec, 1981; see also Benson, 2011). Subsequent elaboration 
specifies that control involves "having the power to make choices and decisions and acting on them", and further identifies three components of the capacity for control: "ability, desire and freedom" (Huang \& Benson, 2013, p. 9, italics in original). Author1 (2017b) notes a fourth aspect: learners' prior awareness of the possibility of learner control. Thus conducive conditions for LA prototypically exhibit the following features: learners know they could and should take control of their learning; they want to; they are able to; and they have the freedom and opportunities to do so.

The shift of control from teachers to learners is a complex, delicate, and challenging process. It is one in which the teacher's power is decreased while "the learner's power [is] concomitantly increased" (Voller, 1997, p. 106) in what may be conceived as a continuum or series of continua (Candy, 1999). Candy further emphasises the deliberate, conscious nature of the teacher's "surrendering of certain prerogatives" and the necessity of learners accepting the responsibility offered. While ideally a simultaneous and seamless process, this handover may not come naturally, and in actuality may require considerable thought and mediative work. The operation of such mediation is, however, scarce in existing literature.

The complexity and delicacy of control shift increases when the teacher's relinquishment is considered in terms of its quality and extent. Candy (1991) highlights the risk of "pseudo-autonomy" (p. 238), when teachers merely go through "the motions of devolving responsibility onto learners" without "commitment or conviction" (p. 237), while Benson $(2001,2011)$ raises the issue of effectiveness in power transfer, in terms of whether the freedom offered is "genuine" and whether learners' decisions have "real consequences" (2011, p. 165). Dam (2011) further identifies other familiar pitfalls encountered by teachers' wishing to embrace LA, such as lack of confidence in students, ingrained habits of teaching rather than supporting, and ready excuses such as "time constraints and having to use a coursebook" (pp. 49-50).

Further complexity and challenges arise in relation to how learners assume control, especially in collaborative groupwork when control is shared among heterogeneous learners. It is generally believed that groupwork shifts the focus from the teacher to students, enhancing learner participation and responsibility (Dam, 2011), creating opportunities for learner interaction and interdependence (Kohonen, 2010) and reducing anxiety (Peterson, 2012). However, there remain concerns relating to quality or effectiveness of learner control, such as pairs not necessarily collaborating (Storch, 2001) and groupwork enabling dependency (Lee, Smith \& Sergueeva, 2016). Concerns have also been raised as to the appropriateness of collaborative learning within the Chinese context (Chen \& Hird, 2006).

As Little (2007a) notes, there has also been considerable debate over the cross-cultural transferability of LA, with claims that it is heavily laden with Western values. Further, even if LA is in principle universally relevant, Benson (2011, p. 70) points out that the associated pedagogical practices may not be. Specifically relating to China, it has been argued that Chinese cultural traits represent "an obstacle" (Ho \& Crookall, 1995, p. 235) to LA, while some Chinese scholars have criticised uncritical adoption of Western concepts (Shu \& Hua, 2009) or failure to contextualise the notion of LA (Shu, 2004).

An alternative position holds that LA has points of genesis in both the East and West which have been nourished in the interaction between the two. Examples are seen in the ancient fundamental Taoist principle of zi zhi (self-governing) and its impact on Carl Rogers (an important source of LA theory, as identified by Benson, 2001), the manifestation of LA in the works of Confucius and Zhu Xi (11301200) (Jin \& Cortazzi, 2006), and belief in real-life active learning as espoused by $20^{\text {th }}$ century education reformer Tao Xing-Zhi, student of Dewey. Thus the notion of LA is well-grounded in Chinese traditions, supporting the legitimacy of current efforts to promote it. 
For empirical research, the sub-issue of capacity for control (awareness, desire, ability and freedom) and pitfalls in control handover (e.g. pseudo-autonomy) provide a starting point for further observation and inquiry. In the present study, evidence and counter-evidence of LA will be identified in learner involvement (e.g. Benson, 2003), authentic target-language use (e.g. Dam, 1995), learner awareness-raising (Nunan, 1997) and reflection (e.g. Little, 2007b), and indications of genuine control release and appropriate learner support (Benson, 2011; Candy, 1991). Learner involvement will include responsibilities in the learning process, including identifying needs and setting goals, selecting resources and methods, defining progression and monitoring progress, and assessing outcomes (Holec, 1981; Reinders, 2010). These features provide observable evidence of actions promoting LA, allowing us to address the lack of empirical evidence in previous studies (Borg \& Alshumaimeri, 2019).

\section{Teachers' cognition and practice about learner autonomy}

To explore teachers' cognition and practice regarding learner autonomy, this paper adopts Borg's (2003) holistic view of teacher cognition, defined as "the unobservable cognitive dimension of teaching - what teachers know, believe, and think" (2003, p. 81), whereby knowledge, belief and thinking are considered an inseparable unit of teachers' mental lives. Teacher cognition research seeks "to understand teachers' minds and emotions and the role these play in the process of becoming, being and developing as a teacher" within broad and complex accounts of their "personal, professional, social, cultural and historical contexts" (Borg, 2019, p. 1167). This aligns with the purpose of the study, in which the aim is not to define teachers' cognitive world or to label its different components, but to understand its complexities, particularly in relation to developing LA through the shift of control, and how teachers' beliefs manifest in, and impact on, their classroom practices. On the whole, teacher cognition is conceived as a dynamic (Woods \& Çakır, 2011) complex system, with personalised, practically-oriented, and context-sensitive features (Borg, 2003). The personalised aspect emphasises the individuality of teachers and their own unique cognitions of varying types and involving different subjects (Feryok, 2010). The orientation towards practice highlights the relationship between teacher cognition and classroom actions, which are "reciprocal, rather than deterministic" (Borg, 2018, p. 86). Both cognition and practices involve multiple dimensions - for example, stated and enacted beliefs; observed or reported practices - which evolve over time (Borg, 2018).

Following Camilleri (1999), the last decade has witnessed an upsurge in empirical studies of teachers' LA-related cognition and practice. With two comprehensive reviews available (Borg \& Alshumaimeri, 2019; Author1, 2016), we focus here on three of the more recent and perhaps influential studies. The first, Borg and Al-Busaidi (2012), highlighted the value in researching teachers' knowledge and beliefs about LA, while lamenting the dearth of such work. Their 37-item questionnaire examined teachers' understandings of LA from technical, psychological, social and political perspectives. This soundly developed and comprehensive survey was subsequently employed in further studies, including a volume of partial replications (Barnard \& Li, 2016) conducted across eight Asian countries. Importantly, these also explored the follow-up professional development workshops, with some (e.g. Wang \& Wang, 2016) leading to further practitioner research, enhancing the practical value of this research. The third, Borg and Alshumaimeri (2019), provides a major contribution in capturing individual English language teachers' conceptualisations of LA "on an institutional scale" and "in a representative manner" (p. 29) through examination of the largest sample to date (359 EFL teachers from one university; 78\% response rate). Nevertheless, as the authors state, a limitation of both this and nearly all previous studies is the lack of qualitative evidence "of how teachers conceptualize and promote learner autonomy", particularly in relation to observation data. Of the 21 studies that Borg and Alshumaimeri (2019) reviewed, only one (Martinez, 2008) involved observation, with the participants being teacher trainees. Borg and Alshumaimeri (p. 29) reiterate that 
a mixed methods approach (see Creswell \& Plano Clark, 2011) would enhance research into teachers' beliefs and practices about LA.

To briefly summarise, then, previous studies highlight the value of LA and emphasise the key role of control shift, a process requiring careful handling. To date, however, there has been little exploration of how control shift happens in practice and a lack of qualitative analyses, particularly of observation data, to support existing research into teachers' LA-related cognition. On these bases, the following research questions were posed:

1) How and to what extent was control shift reflected in the teachers' practices for promoting learner autonomy?

2) How did the teachers perceive their control-related actions and the concept of learner autonomy?

\section{Methodology}

To explore the present research questions, a case study approach was adopted within an interpretative naturalistic paradigm. The following subsections outline the research setting, participants, and methods of data collection and analysis.

\section{Research setting}

The research site was a private secondary school in northern China with approximately 600 students boarding on campus. An approach was made to the school following a colleague's recommendation of the principal's vision and commitment to learner centred education. Central to the school's special character was its treatment of English as a core subject (alongside Chinese and mathematics), as reflected in its name (\#\# Foreign Language School). Nevertheless, like those in public schools, students followed the national curriculum and focused on the national Zhongkao and Gaokao exams (high school and university entrance exams). Classes comprised 24-36 students each (compared to typically 40-60 in state schools), all native speakers of Chinese. The principal was a nationallyrecognised school administrator with considerable experience and a US-obtained doctorate in education. The founding principle of the school was to combine academic success with well-rounded personal development. To this end, the school's guiding document specified three aims: collaboration, efficiency, and - most notably for present purposes - LA. These were supported by documented education principles, classroom implementation procedures, and measures to support teachers (for details see Author1, 2017b). The implementation of such policies was guided by the academic director, who had been recruited mainly on the basis of his previous experience promoting LA.

Being a private school, students were mostly from the middle- or upper-economic bracket, and the higher tuition fees undoubtedly raised parental expectations of educational quality. Being a private school also allowed for greater freedom in the recruitment and management of staff (e.g. higher salaries and an internal performance-review-and-reward system). Most teachers held a bachelor's degree and many brought substantial skills and experience as programme leaders. Overall, then, the school appears to represent the type of extreme and unique case which usefully serves as a "test bed" (Robson, 2002, p. 182), such that it may fairly be assumed that if the school's attempt to develop LA was ineffective, then the odds are against its success elsewhere.

An interesting feature of the school were the scheduling of weekly 'open lessons'. These were open in the sense of having an open-door policy for anyone to observe the designated teacher's lesson, including outsiders such as parents. Other English teachers were obliged to attend, and it was understood that management and teachers from other departments would also attend on occasion. Each open lesson was followed by a feedback session, which typically involved a rather frank critique and suggestions for development (Author1, 2017a). Each teacher conducted at least two open lessons 
per semester. As a source of observation data, there are three particularly notable aspects of these lessons and discussions. Firstly, since open lessons were by definition scheduled for observation entirely independently of the researcher's presence, there is a stronger sense of ecological validity than typically found in similar studies. Secondly, while events do unfold differently under observation (the observer's paradox), this is somewhat mitigated by open lessons being a routine practice at the school. Thirdly, since the feedback was often rather direct and critical, it may be presumed that teachers were presenting lessons designed to showcase their understanding and application of LA principles and/or groupwork features; it may be that their ordinary practices were less reflective of LA than witnessed in the open lessons.

\section{The participants}

The school's nine English teachers were informed of the project at a staff meeting and all volunteered to participate, thereby enabling a case study of a full academic department. Their willingness to do so probably reflects their experience and familiarity with observation: the researcher was just another observer on the day. Also participating in the broader study were the principal and academic director, both strong advocates of LA. Each teacher taught two classes (twenty 40-minute lessons per week) and was also assigned peer observations and subsequent feedback sessions (3-4 hours per week). Details about the teachers' qualifications, experience and positions within the school are presented in Table 1 (Appendix 1).

\section{Data collection procedures}

Data were collected over an entire 18-week semester through classroom observations (videorecorded; mainly open lessons), audio recordings of post-lesson discussions and individual interviews, and documentary analysis (e.g. curriculum, lesson plans). All nine teachers were observed at least twice each, totalling 22 observed lessons (nineteen open lessons; three ordinary lessons). Also recorded were the scheduled post-lesson peer feedback sessions, and in fourteen cases these were followed by one-to-one discussions with the lead researcher. At the conclusion of the semester, a final interview was conducted with each teacher, and it was only at this point that the research focus on LA was revealed to the participants. Additional interviews were conducted with the principal (once) and the academic director (twice). The discussions and interviews were conducted in Chinese.

\section{Data analysis}

Data analysis was based on Glaser and Strauss' (1967) Grounded Theory and facilitated by NVivo 10. To examine control transition, it was important to firstly make sense of the 22 lessons in terms of broad themes and components. To this end, videos of each lesson were coded minute-by-minute from various perspectives, with links made to observation notes. These codes were tabulated in various ways, amongst which, three tabulations proved particularly insightful: (1) an overview of all the 22 lessons showing the learning tasks of each lesson (e.g. 'reviewing grammar rules for plural nouns') and the allocated times, (2) closer analysis of each major task focusing on how it was conducted in terms of phases and participant roles, from which three main teaching approaches were identified (discussed below), and (3) closer scrutiny of each approach to identify the nature and degree of learner involvement (e.g. self-study; group/pair work). These provided valuable insights into the overall organisation of activities within the classroom and as a way of identifying and classifying lesson phases. Example extracts from the latter two tabulations are provided in Appendices 5 and 6.

Once the broader scope had been established, focus then turned to transcription and close turn-by-turn analysis of actions within particular episodes that seemed ostensibly LA-related. As illustrated in the findings, particular attention was paid to indications of teacher and learner control and other LArelated factors such as actions and responses (e.g. directives and verbal/physical responses), language choice (Chinese or English), and authentic language use.

Interviews and post-lesson discussions were transcribed in full and, with school documentation, were analysed thematically through processes of open and axial coding (Charmaz, 2006; Strauss, 1987), 
constant comparison (Harding, 2013; Strauss, 1987), and iterative checking (Seidel, 1998). Where these directly related to specific actions within lessons, links were made within NVivo. Within the wider project, the accuracy of data transcriptions and quality of data analysis were monitored throughout by doctoral supervisors. Specifically for the purposes of this paper, the data analyses were conducted and agreed upon by both authors, thereby combining the insider perspective of the first author (who spent months 'on the ground' at the research site) with the outsider perspective of the second author. Throughout this process, we challenged one another for robust evidence for all claims and actively sought counter evidence.

\section{Findings}

This section reports findings about the English teachers' practices and cognitions in relation to promoting LA, first in brief overview of all nine teachers' practices (observed and reported) and then in greater detail for two teachers (T2 and T3). Data sources are coded as follows: observation (O), post-lesson discussions (PLD), departmental open discussions (OD), interviews (I), and field notes (FN). The observation data reveal classroom practices, with other sources revealing the teachers' rationales for the practices and their general understanding of the notion of LA.

\section{Observed and reported practices: An overview}

Observation of teachers revealed three common approaches which appeared potentially conducive to the development of LA through promoting students as the main agents of activity. Here, these are labelled pre-lesson presentations, collaborative group learning and student-led peer teaching. The pre-lesson presentations were lesson starters in which students, individually or in teams, presented on a topic that was independent of the main body of the lesson. Introduced by Teacher 1 and subsequently adopted by eight of the nine teachers, students were involved in such ways as selecting or developing their own topics and resources, presenting (individually or in teams) followed by questioning and answering, vocabulary teaching, peer error-correction and performance evaluation. Collaborative group learning, as it was labelled within the school, had been introduced by the academic director as an instructional model to support LA and was used by all teachers. It involved phases of individual self-study, group discussion, group presentation, peer feedback, peer evaluation, and individual internalisation; these were labelled by the director as six phases in a collaborative knowledge construction cycle. An extension of this, adopted by three teachers, was student-led peer teaching, in which students (co-)planned and delivered an assigned teaching task (for details, see Author1, 2016).

Other apparently LA-facilitating practices were discussed by teachers but not observed. These have been grouped into five types and are presented in Table 2 (Appendix 2). Examples include students monitoring one another's progress through peer dictation and text recitation, comparing answers and tackling errors together, peer marking and feedback-giving, and developing autonomous and collaborative study skills. Although not observed, they were reported to be routine; the detailed manner in which they were described suggests that they were at least used on occasion. Overall, it appears that substantial efforts were directed towards creating opportunities for active learner involvement.

Findings from a detailed scrutiny of all 22 observed lessons are presented in overview in Table 3 (Appendix 3) in terms of the approaches different teachers adopted and the LA features embedded in each approach. This makes possible a broad characterisation of each teacher's attempts at promoting LA. For example, as will be discussed in more detail, the promotion of student involvement appears deeply embedded in Teacher 2's (T2) practices, extending to areas not observed or reported for the other teachers. Conversely, the practices of another teacher (T6) appeared to have little student 
involvement, suggesting little orientation towards genuine LA development despite utilising the three LA-conducive teaching approaches common within the school.

In what follows, we examine more closely the practices and beliefs of two teachers. In examining less successful LA-promotion, we leave aside T6, who allowed for minimal student control, and T7 and T9, who seemed reluctant to adopt the promoted groupwork instructional model; we opt instead for T3, who professed to strongly support LA but whose actual practices seemed contradictory. Attention then turns to T2, who appeared to have the most deeply embedded LA practices.

\section{T3: "Maybe, unconsciously, I'm quite dominant"}

Among all the teachers, Teacher 3 (T3) appeared the most enthusiastic in both welcoming and implementing the school's teaching innovation, particularly in relation to the director's group study model. Over the semester, she frequently utilised groupwork, with considerable emphasis on discussion and presentation, together with the awarding of 'points' for worthy performance in a manner closely resembling the director's model. She was later selected to represent the department as one of two 'best groupwork practitioners' in a school teaching competition showcasing the promotion of LA. However, analysis suggests that her practices supported LA in only very superficial ways and at times actually subverted it. In illustrating these practices, we narrow our focus to close analysis of episodes within one phase (presentations), within one particular lesson.

\section{Episode 1}

The episode below illustrates a typical example of T3's employment of the group study model. This occurred at the start of a lesson in a phase lasting approximately fifteen minutes. The activity was a group presentation on plural noun rules, conducted in four steps. First, two or three students from each group wrote the grammar rules on the blackboard. Another group member then led the class review with explanations and/or examples; T3 termed this the presenting/showing (zhan shi) session. Other students were then invited to comment, termed the questioning session. In the fourth step, the teacher awarded groups points for contributions she judged to be valid (T3.L1.O). Below, and elsewhere, italics indicate a translation of the original Chinese (with full scripts presented in Appendix 4).

\section{Observation Extract T3.L1.E1}

01 S1: Group Zhang [a surname] is to present, er, er, the general ones are [T interrupted]

02 T: What is your presentation about?

03 S1: categories, forming methods

04 T: categories, forming methods of what?

05 S1: nouns

06 T: What kind of nouns?

07 S1: er er er, categories, forming methods of plural nouns

$08 \mathrm{~T}$ : uncountable nouns ' plural forms?

09 S1: plural nouns

10 T: Ok, go. make it clear.

11 S1: -s, for general nouns, add -s, book, books, bed, bed[s], and boy, boys

......, words with consonants /IIIII

12 T: You can look at the word following

13 S1: er er er

14 T: Its rule is summarised from special words, look at family, how is it changed? ok?

15 S1: / er er er // add er, er er

16 T: Ok, don't be nervous. Don't be nervous, you can't do it, it's ok. go on.

17 S1: Just this one?

18 T: $\quad$ Yes $\uparrow$

19 S1: er family, families, oh, no 
As confirmed in the post-lesson discussion (T3.L1.PLD), this episode illustrates T3's adoption of three phases of the director's suggested group study model: presentation (written and oral), peer feedback, and evaluation. For present purposes, two main issues are worth noting. Firstly, the working language (written and spoken) was Chinese, with English minimally used and limited to the actual words/examples being presented; this lack of opportunities for authentic language use conflicts with principles of LA. Secondly, the presentation adhered to a highly structured and routinised format directed by the teacher, as suggested by her use of formulaic remarks for opening (Group X is to present), closing (That's all for Group X's presentation), and making additional points (Group X to $a d d$ ). Indeed, her directive comments appeared to have a puppeteer-like control over student movement, suggesting a well-drilled routine with little room for students to initiate independent actions. For example, when shortly after she said "Now, discuss", students responded promptly, heads huddled closely together, suggesting they knew exactly when to talk, to whom and about what; similarly, when the teacher announced that the presenting phase was to start, the three groups at the back of the classroom flocked to the front and crouched down; and when one group was presenting, representatives of other groups queued for their turns (T3.L1.FN). These actions caught attention because they so closely mirrored the director's "groupwork operational tips" (Teacher Training Booklet. \#7.8). Such highly structured sequences of activity are strongly suggestive of the students having been trained in how to respond to the teacher's cues, especially given their occurrence at the start of semester. The highly constrained nature of the activities suggests extremely limited opportunity for student control.

Teacher 3 provided her rationales in the post-lesson discussion, though these were not aligned with her actual practice. First, she expressed great enthusiasm for the group study model, which she said suited her teaching style very well. She expressed confidence that her students loved group work and participated actively. She cited the following saying about idea-exchange: If you have an apple and I have an apple and we exchange apples, then you and I will still each have one apple. But if you have an idea and I have an idea and we exchange these ideas, then each of us will have two ideas ${ }^{1}$ (T3.L1.PLD). She also expressed a distinctly positive attitude towards the group work formalities, as indicated in the following statement of purpose: "Students of this age are lively by nature and full of

\footnotetext{
${ }^{1}$ Originally, by George Bernard Shaw (https://en.wikiquote.org/wiki/Talk:George Bernard Shaw); T3 did not mention the source.
} 
energy, so get them moving, and keep them busy; huddling heads together was like a signal, which put them into immediate action" (T3.L1.PLD). She believed the "questioning' session provided opportunities for students to learn from one another's strengths and weaknesses, and she particularly highlighted the importance of "learning from mistakes": "I welcome students' mistakes. The more exposed, the better. If they could spot and correct the mistakes in everyday study, they won't get it wrong again in exams" (T3.L1.PLD). In addition, she felt the feedback session could "hold students' attention" and therefore "enhanced students" participation and engagement". The awarding of points was intended as a means of peer evaluation which would facilitate autonomy through critical thinking; in practice, she often awarded the points herself and only did so for strong performance "to see how well students had mastered the learnt knowledge" (T3.L1.PLD).

\section{Episode 2}

The strong sense of teacher control is supported in analysis of the following extract, involving a 'tugof-war' with the third presenter. This followed a sudden and arbitrary decision by the teacher that this particular student (unlike previous ones) should perform his presentation without reference to the group's blackboard notes. This occurred in the midst of the presentation session, following the second presenter's turn. At the beginning of this extract, the student was about to start; the phrase "this time" (Turn 01) refers to the third presentation by the group. Bold indicates vocal emphasis:

\section{Observation Extract T3.L1.E2}

$01 \mathrm{~T}$ Ok, now Group Yue, [...] Now they've presented for two times, now this time, [xxx], you'd better tell us without looking at the blackboard. Do you understand?

02 S4 Yes. [S4 was about to start].

$03 \mathrm{~T}$ You'd better tell us without looking at the blackboard. Without, without looking at the blackboard [T using gestures to illustrate the idea not to look at the blackboard.]. You just look at us. Yes $\uparrow \mathrm{Ok}$, go.

[S4 turned to the blackboard and was to start.]

04 T Don't, don't look at the blackboard [T's voice raised sharply]. Look at us. Yes $\uparrow$ Ok. Look at us.

05 S4 Er, er [S4, still looking at the blackboard, was starting to read.]

06 T No. Without. [T using gestures to illustrate the idea not to look at the blackboard; ss laugh.] Don't look at the blackboard. Yes $\uparrow$ Ok. Go.

07 S4 Group Yue is to present [...] [S4 ignores T's instruction and starts to read from blackboard.]

08 T No, don't look at the blackboard. Don't look at the blackboard. Just look at us.

09 S4 singular countable nouns change plural, add $s[\ldots]$ [S4 finally moves his eyes away from the blackboard and faces the class talking, but shortly gets stuck and turns back again reading from the blackboard. Ss laugh and laugh.]

$10 \mathrm{~T}$ Now don't look at the blackboard.

11 S4 then with the ones without s [...] [ignoring T's insistence, S4 continues to read from the blackboard.]

This episode highlights the constraints T3 imposed around activities in which students were ostensibly meant to be developing autonomy. The apparent handover of control in Turn 01 is prefaced 
with the instruction "you'd better tell us without looking at the blackboard", closely followed by "Do you understand?", which appears designed to elicit agreement to comply. The teacher follows with a series of further turns which reiterate this instruction; these interrupt the student's projected action no fewer than five times (Turns 03, 04, 06, 08, 10), beginning with two repetitions of the initial indirect instruction (Turn 03), followed by a series of imperatives in the following turns. Thus, while seeming to have released control for the student to present his answer, the teacher persistently interfered with the process, asserting firm control over the activity.

The post-lesson discussion reveals some of the LA-inhibiting dimensions of the teacher's thinking. Strikingly, she accounted for her instruction as an impromptu decision to "deliberately" make the task more demanding "for the purpose of taking the opportunity to develop students' attentive listening". The presenter was a student she described as "relatively slow and weak", and "it was an open lesson with many observers, so he might be quite nervous" (T3.L1.PLD); under such circumstances, T3's sudden insistence that he not refer to notes as planned seems to inexplicably undermine his public (open lesson) performance. T3 further described the student as "very peculiar and different from others", yet rather than accommodating this individuality, she said "I just wanted to straighten him out". Reflecting on this, she observed that "I might be a very dominant character and want to take control" and that her way of managing students might be a reflection of her "inner-heart thinking". This particular student gave her a "headache" and she admitted being preoccupied with "how to change him", yet despite trying "all sorts of ways, still [she] can't control him" (T3.L1.PLD). These and other reflections by the teacher, both on and within this episode, appear to expose a strong hidden desire to control the class and students, little awareness in catering for students' individuality, and suggest little genuine understanding of the nature of LA.

\section{Episode 3}

As a final illustration of LA-subverting behaviours in the presentation session, it is worth briefly mentioning how T3 closed this phase of the lesson. Six groups had written their rules on the board and were scheduled to speak. However, T3 abruptly terminated the activity after the third, while the fourth group stood awaiting their turn (T3.L1.O). To terminate a previously understood sequence of turns in this way appears a powerful assertion of control$^{2}$. In doing so, the opportunity for learnerbased activity was sacrificed - and the learner's pace of learning ignored - to accommodate the teacher's agenda, far from the ideal of "a negotiated agenda" (Trebbi, 2003, p. 235).

\section{General beliefs \& summary}

It is frequently the case that teacher beliefs and practices diverge (Gross, 2015) and typically this in itself would barely warrant discussion. However, the present case seems remarkably divergent. T3 stated her basic understanding of LA as involving students taking an active role in their learning: "Autonomous learning is to change students from being passive to being active (zhu dong). Let them be the agents (zhu ti) in class, participating actively rather than just listening to teachers passively. [Autonomy] is the inner drive (dong li) [for someone] to act on his own (zi ji)" (T3.I). She claimed strong belief in students' capabilities for independent learning and a determination to release control to students with no concern about classroom management issues: "Students are very smart. I believe they can solve many problems by themselves. I love to get students working busily in groups. I let them go in their own way. I don't mind the class looking chaotic, as long as students are actively engaged" (T3.I). As should be evident, these professed beliefs stand in stark contrast to those actually enacted in the episodes discussed above.

\footnotetext{
${ }^{2}$ By way of comparison, it seems inconceivable that a student could enact such a termination.
} 
To briefly summarise, then, we have presented a case in which the teacher claimed both an affinity for LA and was lauded within the school for her LA-promoting practice, and yet analysis of her practices indicates they were in strong opposition to LA. Rather than building an argument based on cherrypicked incidents, we have focused on episodes drawn from a sequence of actions within a single (showcase) lesson. The episodes here illustrate respectively (1) a sequence involving a very tightly controlled format with very little opportunity for learner-initiated activity and little use of English, (2) a sequence in which the handover of control to a student occurs only with the imposition of an arbitrary constraint and persistent interruptions to reinforce it, and (3) a brief description of the abrupt termination of the lesson phase, representing an assertion of control preventing half of the planned student contributions.

\section{T2: "I know the core ideas and embed them into my teaching. ... Students did well, often much beyond my expectations.”}

Among the nine teachers, $\mathrm{T} 2$ appeared to have the most consistent and deeply-embedded approaches to promoting autonomous learning, as partially suggested within the overview of teacher practices in Table 3 (Appendix 3). She provided a wide range of opportunities for active student involvement, appropriately facilitated student-controlled activities, and attended to students' needs for both free authentic communication and cultivation of autonomous study skills. She spoke eloquently in providing sound rationales for most of her LA-related practices, expressing trust in learners' potential to be autonomous, and demonstrating an astute understanding of the nature of LA.

\section{Episode 1}

The following episode is taken from the opening minutes of T2's first open lesson of the semester, in which a student is selected to give a pre-lesson presentation involving the retelling of a learnt text. This selection process was jointly conducted with students through T2's question prompts and achieved entirely in English.

Observation Extract T2.L1.E1

[Class commences. Students stand and greetings are exchanged].

$01 \mathrm{~T}$ Just now a few of you said Group 1 and Group 6, only few of them recited the text. Now, I just wanna choose one. Group 1 and 6, which one?

02 Ss One, one $<$ six, six, six $>$. [ss yelling different numbers]

$03 \mathrm{~T} \quad$ Okay, Group 6. Number ---

04 Ss Three three three $<$ four four four four $>$. [ss yelling different numbers]

$05 \mathrm{~T} \quad[\mathrm{xxx}]$ has done $[\mathrm{xxx}][\mathrm{T}$ bends to check with a student in the front.]

06 Ss Four four four [ss yelling]

07 T Okay Four. Number 4. Welcome. [ss clap hands; a boy student comes to the front.] Which passage?

08 Ss $\quad[\mathrm{xxx}]$ [ss giving T suggestions]

$09 \mathrm{~T}$ Ok the newest.

10 Ss $\quad[\mathrm{xxx}][$ ss yelling] 
$11 \mathrm{~T}$ Oh Jenny Ian. Do you remember? [T giving prompt to start] Do you remember Jenny Ian ---

12 Ss $[\mathrm{xxx}][$ ss chorus the text]

$13 \quad \mathrm{~T} \quad$ Shiiiiiii [ $\mathrm{T}$ focuses attention on the presenter]

14 S1 Do you remember [...] [the boy recites the text]

A turn by turn analysis of this brief episode proves revealing. Prior to the extract presented here, there was noise and chatter among students before the class stood and greeted the arriving teacher. As revealed in Turn 01, T2 had evidently gathered from the student chatter that Groups 1 and 6 were due an opportunity to present, and in Turn 01 she narrows the selection options to these two. Students respond in Turn 02, with calls for Group 6 being louder and more numerous, to which T2 concurs. In Turn 4, the students then call out various student numbers, of which Three and Four are the most perceptively prominent. At this point (Turn 05 ), partially drowned out by voices, T2 points out that one of the candidates (perhaps Student 3) has presented previously. Calls for Student 4 then become overwhelming and $\mathrm{T} 2$ calls him to the front. This is mirrored elsewhere with the teacher acceding to the most popular nomination for a text to read. At this micro-level of decision-making, we see a degree to which the teacher invites students to individually contribute suggestions, with the most popular choices likely to be adopted. In this way, although undoubtedly wielding the real power, the teacher ostensibly acts as the chair, generally approving the options arrived at by student consensus, and - crucially - providing a rationale for discounting some of the proposed options (Lines 01 and 05). The result is shared control in selecting the presenter and the text.

This aligned with the beliefs T2 articulated in the post-lesson discussion, where she spoke of valuing learner empowerment and trusting in them to take opportunities. In delegating some decision-making, she "transferred part of [her] teacher authority to students", believing they would "exercise the given power in a desirably positive way". She added: "I trust them; they are positive and upright; and they choose the most difficult section to challenge their fellow classmates" (T2.L1.PLD).

The ensuing activity involved the presenter retelling the selected story, not word-for-word, but with "flexible changes" to "practise using the learnt language in the text" (T2.L1.PLD), thereby allowing for the exercise of agency. As audience members, students were asked to "listen attentively, compare with what's in their own memory, and spot any mistakes in the reciting and suggest corrections" (T2.L1.PLD), thereby allowing for collaborative control (peer monitoring) over learning outcomes. The task was achieved entirely in English and for both the presenter and audience promoted a degree of autonomous language use. In the post-lesson discussion, T2 emphasised the communicative function of language embodied in the design of the presentation task and, for the audience task, she professed to focus more on the process of self- and peer-checking than on the actual errors, stressing the opportunity to develop study skills: "learn to be a good listener", by way of "showing respect to the speaker first of all, and keep one's thinking actively involved" (T2.L1.PLD).

\section{Episode 2}

Another approach T2 adopted was collaborative group learning. This was employed in both the observed lessons, with the second (more comprehensive use) illustrated here. The lesson objective was "to use the simple past tense to talk about the past" (T2.L2.Worksheet). The lesson was composed of the following phases:

Step 1. warm-up chat

Step 2. autonomous ( $z i z h u)$ learning: checking past tense verbs and time expressions

Step 3. talking in groups and with the teacher about "My life two years ago"

Step 4. individual writing and editing

Step 5. peer sharing and editing 
Step 6. reading (T2's composition)

Step 7. redrafting their composition (T2.L2.O; T2.L2.Worksheet).

T2 led the warm-up chat in Step 1, with the topic flowing from that day's weather to the previous day's, and then to an earlier school event. In Step 2 (autonomous [zi zhu] learning), students first worked silently on three worksheet tasks focusing on verb forms and past time expressions, before checking their answers against a key. In Step 3, students used the time expressions, talking firstly in groups about their past experiences, and then with $\mathrm{T} 2$ about their primary school experiences (T2.L2.O). As preparation for writing, they individually wrote key sentences about these experiences before the teacher nominated some to read theirs aloud. She then elicited ideas based on prompts from a writing outline presented in PowerPoint, such as "where/what you studied, how you got to school, happy or not" (T2.L2.PPT). In Step 4, the actual writing session, students were instructed to (re)organise their thinking, write their own draft and then self-edit. During all writing stages, the teacher circulated around the classroom but did not interact with students. In Step 5, students swapped their writing with a group member to "learn the strengths from others and help them identify problems, and then note down good sentences from their writings" (T2.L2.Worksheet). With time up, $\mathrm{T} 2$ assigned her own sample writing as reading homework (Step 6), to be followed by students redrafting their own work (Step 7) (T2.L2.O).

Among LA-promoting features, the lesson contained a series of independent and collaborative learning opportunities, in which students were taking or sharing control and exercising agency. The former included opportunities for self-trial (e.g. individually working on verbs, sentence writing, extended writing), monitoring/assessing (independently checking with answer keys), reflection (selfediting) and reconstruction (reorganising and rewriting). Agency was exercised in the two groupwork sessions (talking in groups; peer-reviewing first drafts). When control shifted to students, T2 provided guidance and support for content/meaning (e.g. warm-up chat about the past; targeted writing topic) and language (lexical, syntactic, and discoursal levels). Opportunities for autonomous language use were evident in the warm-up chat, which invited authentic communication from students. Evidence of student empowerment may be detected in the teacher performing the same writing task as a sample, revealing something of her own personal history, while eschewing more grammatically and stylistically complex language (which would have reinforced her status as the expert language user) in favour of level-appropriate language to which the students could reasonably aspire.

In the post-lesson discussion and interview, T2 articulated largely sound rationalisations for Steps 1-7. She explained her scaffolding actions in Steps One to Three as being "step-by-step building-up to prepare students for the subsequent first draft writing" (T2.L2.PLD), with both the informal chat at the beginning and her own story being planned. In both, she had the dual purposes of "catching every possible opportunity to have real-life communication" and "putting [herself] among students", insisting that "the primary purpose to learn a language is for communication rather than examination" and "good rapport with students inspires and motivates them and facilitates their learning" (T2.L2.PLD).

She further emphasised self-study and discussed various self-based activities she that she had used in her own language learning. She stated that she found self-study "the most efficient way of learning", in that it is "self-reliant" and hence "unconditional", and readily "conducted anywhere anytime". Subsequently, she emphasised the benefits of group work, stating that "discussion clarifies one's own thinking and stimulates and inspires each other's", and that "group work increases participation" through offering different roles to more and less skilled language users (T2.L2.PLD). She also stressed the value of cognitive processing: "Whether new knowledge is constructed autonomously (zi zhu) or collaboratively ..., the very last step must be self-internalisation. Only through a self-digestion 
or reflection, can what you have learned become genuinely your own, and can you then use it freely" (T2.I).

In relation to peer-marking and editing, $\mathrm{T} 2$ commented that "it did not matter much what mark they gave to each other; but to make a judgement, they needed to think critically" (T2. L2.PLD), a view of critical thinking aligned with the LA literature. On the use of performance points, as promoted by the director, she said "when using such points the teacher must have an genuine intention to give control to students" and that in her "experience as long as [she] seriously gave, [her] students seriously took the power to judge [other students' work]" (T2.L2.PLD, bold indicating emphasis).

\section{Episode 3}

It is, however, also worth briefly acknowledging a practice observed on one occasion which appeared to undermine T2's control handover. As students planned and wrote their first drafts, T2 persisted in talking, providing further instructions or reminders such as "don't haste to write; reorganise your thinking". This deviated from her stated beliefs and is a practice she had been critical of in another teacher's open lesson (OD1). When asked about it in the interview, she expressed surprise and was evidently unconscious of doing so.

General beliefs \& summary

Overall, T2 demonstrated deep understanding of principles of LA. She described autonomy as " $a$ capacity to act independently [du li], analyse and solve problems by oneself [zi ji], with or without external help available" and "an inner strength that keeps people calm and confident in all situations" (T2.I). She stressed that "autonomy influences one's way of saying, doing, and thinking, that is, character forming" and that "it is something hard to describe, but comprehensively good for one's wellbeing" (T2.I).

While space constraints prevent detailed presentation of other relevant findings, the preceding episodes should provide ample evidence that $\mathrm{T} 2$ shifted or shared control with students in ways that promote a degree of LA in distinct contrast to the practices of T3. The episodes discussed here include (1) close analysis of a sequence of talk revealing LA-conducive actions at the micro-level of teacherstudent interaction over selecting materials and presenters: $\mathrm{T} 2$ responds genuinely to the will of the class and the ensuing activity involves autonomous language use and peer feedback; and (2) analysis of a near lesson-length sequence of activities involving multiple dimensions of LA-promoting practice, including independent and collaborative work, authentic language use, peer feedback, and opportunities for exploration and reflection. Conversely, a third episode also reveals evidence of T3's behaviour placing unconscious constraints on LA.

\section{Discussion \& implications}

\section{Contribution of mixed methods with observation data}

The present findings investigate language teachers' beliefs and practices relating to the promotion of learner autonomy in the context of Chinese curricular reform, and in so doing respond to Borg and Alshumaimeri's (2019) call for the use of empirical evidence and mixed-methods. The contribution lies particularly in the utilisation of empirical data from multiple sources to examine two contrasting case studies, from which detailed pictures emerge of how the two teachers facilitated (or inhibited) learner control and how they accounted for their practices in both their reflections on specific actions and their more general beliefs about LA. In relation to their practices, the analyses reveal ways in which control was withheld or released at various levels of classroom activity, from micro-level moment-by-moment decision-making to larger sequences of organised activity. In relation to their beliefs, interviews and post-lesson discussions elicited teachers' perceptions of their practices and other claims about their underlying orientation to LA. 
Strengthening the present findings are three features of the research design. Firstly, the focus on LA was only made explicit to participants in the final interview, thereby minimising the influence of response bias. Secondly, the observations were of 'open lessons' planned and scheduled for wider observation rather than for research purposes; these entail a 'showcase' element of what the teachers consider sound teaching (see Author1, 2017b). Thirdly, participation involved all nine English teachers, the principal and director ${ }^{3}$, and access was granted to an extensive range of activities and documentation; the two case studies were selected for their illustrative power and representation of ${ }^{4}$ contrasting positions on LA.

Alongside these strengths, there are limitations in the extent to which case study findings may illuminate other contexts. Further, although the total number of observed lessons is fairly large compared to previous studies, each teacher was only observed between two and four times, with T2 observed twice and T3 three times. Future studies might usefully explore a series of consecutive 'ordinary' (rather than 'open') lessons by fewer teachers, which may present a more detailed picture closer to those teachers' everyday practice.

Other promising areas for future research would include similar designs conducted in public schools, with a particular focus on in-service PD. This would enhance understanding of contexts that may be less supportive of LA initiatives. Of further interest would be empirical studies from a later date, when practitioners and students may have had more exposure to LA.

\section{Complexity and delicacy in control shift}

Among all nine teachers, evidence of control shift was identified in most lessons but varied in degree and manner from teacher to teacher and from lesson to lesson, representing a spectrum of control release (Candy, 1991). Teachers 2 and 3 represent contrasting positions along this spectrum. T2 was observed to offer the most genuine and abundant opportunities for student control, with these practices aligning with her beliefs about LA. Control shift was both planned (at the levels of overall lesson and task design) and responsive (at the level of moment-by-moment decision-making). By contrast, T3 maintained tight command over events, which stood in stark contrast to her strongly professed support for LA principles ${ }^{5}$. When seemingly releasing control, she promptly reclaimed it (e.g. the 'tug-of-war' episode) in what amounts to false or pseudo control release (Candy, 1991; Dam, 2011). In such ways, ostensive LA represents a delicate state in which student decision-making is tightly constrained and the teacher retains a conspicuous, ever-present authority to intervene at whim.

An important issue to emerge from these findings is evidence of what we label masked teacher control within ostensibly student-led activities. In such cases, deeply-rooted teacher control is merely shrouded in a few trappings of LA, whether to manage audience impressions (as may happen under observation) or to preserve the comfort and familiarity of command (as may also be the case here). For instance, in T3's presentations and peer-comment sessions, students had been trained to follow highly-uniform procedures and signals, with this rigid format presumably instilled in previous lessons. Thus, while the near absence of teacher-talk outwardly resembles control shift, the weight of the

\footnotetext{
${ }^{3}$ see also Author1 (2017b) for discussion of the beliefs and practices of school management.

${ }^{4} \mathrm{~T} 2$ was the teacher with the most effective and deeply embedded LA practices and beliefs; among those who professed LA-aligned beliefs, T3's practices were less LA-facilitative.

${ }^{5}$ It is worth reiterating here that T3's practices were far from the least LA-aligned, with Teachers 6,7 and 9 all demonstrating more traditional teacher-centred practices and in some case expressing LA-resistant beliefs.
} 
teacher's invisible control in fact suggests an even greater than usual underlying dominance. In such cases, apparent learner control is a delicate veneer over deeper structures of teacher control.

This spectrum of practices can be plausibly traced to aspects of the participants' beliefs, understanding and identity within the context of Chinese educational reform. Overall, T2's practices had the clearest alignment with her beliefs: her displays of trust in learner capacity for autonomy mirrored her expressed understanding of the concept of LA, her greater awareness of related pedagogy, and sounder rationalisation for her practices. As exemplified above, she articulated these in ways that appeared relatively novel, suggesting she was verbalising an internalised understanding rather than merely reciting platitudes. A key factor appears to be her confidence and autonomy as a teacher: she occupied a leadership role at the school, was held in high esteem by staff and students, was the most proficient in English, and had previously taught at a university. It seems likely that her professional confidence made it easier to shift control to learners, knowing that she could comfortably manage the situation. It may also be that she had a personal affinity towards LA: she spoke of being an autonomous learner herself, and of autonomy and independent problem-solving being among her family's values.

The misalignment in T3's practices and stated beliefs can be similarly be traced to corresponding factors. Despite her expressed enthusiasm towards LA and a general understanding linking it to learner-centredness, her articulation was much less convincing, largely appealing to familiar dictums such as "learning from mistakes", "active rather than passive learning" and "students are capable". These suggest a more superficial understanding. Our impression is that they were newly adopted beliefs (probably prompted by the school-wide LA initiative) that T3 had not yet reconciled with her established practices and implicit understandings ${ }^{6}$. Her own educational experience would have been very much teacher-centred, likely forming the core of her understanding to which some trimmings of LA were overlaid. Also worth noting is the likely role for T3's professional identity in the enactment of her beliefs: her recent appointment to the school represented a significant career promotion and she was undoubtedly striving to make a strong impression. Somewhat lacking confidence in herself and her students, she kept to her tightly organised lesson plan, seemingly a safe option in front of a dozen observers including the director.

Beyond LA, the present findings suggest wider implications within contexts of educational reform and innovation. Recognising the need for shifts in thought and practice, the school had put in place a seemingly comprehensive PD system based particularly around modelling teaching approaches, and post-lesson discussions of open lessons. However, there was limited ongoing discussion and structured reflection on the underlying principles. Without this deeper understanding, while T3 was still able to follow the steps provided in the teaching models (recall that she was put forward by the department as a model of best practice), closer examination reveals that her moment-by-moment decision making was counterproductive, particularly at the micro-level of shifting control. As Watanabe (2017) argues in her expansion approach to professional development, true development involves not only acquiring new techniques, but engaging deeply with one's understandings around practice, theory, identity, students, and context. In short, it seems that successful educational reform is likely to require substantial support for development in teacher cognition.

\footnotetext{
${ }^{6}$ In such cases, the most effective professional development may be reflective practice that focuses on the alignment between beliefs and practice (Farrell \& Ives, 2015); T3's post-lesson reflections already included the realisation that "maybe, unconsciously, I'm quite dominant", which suggests an impetus for development.
} 
Complimenting the present study of control shift, it would be worthwhile for future empirical studies to explore teachers' practice and cognition in relation to supporting learners' to actually accept or take control.

\section{Feasibility of LA in conventional non-Western classroom settings}

As outlined in the literature review, a constellation of factors is required to effectively support LA (e.g. learner involvement, authentic language use, awareness raising) and this raises the crucial question of how feasible LA is within a given context. Cortazzi and Jin's (1996) influential work on cultures of learning has further clarified that pedagogical practices that are successful in one context may lack transferability to another. In this vein, it has been remarked that aspects of Chinese educational culture present obstacles to the implementation of LA (Ho \& Crookall, 1995), and even that LA may be "inappropriate" within some social and political contexts (as reported by Little, 2007a, p. 11) 7 .

However, the present findings demonstrate that LA can indeed be fostered in conventional classrooms in ways consistent with how it has been operationalised previously (e.g. Chang, 2007; Chen \& Hird, 2006; Dam, 1995). This includes student involvement in selecting topics and materials, individual collaborative inquiry, communicative language use, self/peer-monitoring, and peer feedback. Control shift was further identified in areas such as classroom management, for example stronger students assisting teachers with classroom interactions or managing student records.

Assuming institutional support, the crucial factor in the feasibility of LA thus appears to be the moment-by-moment enacted beliefs and other actions of individual teachers. The contrasting cases of $\mathrm{T} 2$ and T3 reveal striking divergences in conducting similar tasks in similar contexts, which either facilitate or impede LA. Questions of the feasibility of LA should not, therefore, be settled a priori with reference to generalities such as culture and setting, but be deduced from the beliefs and practices of the teachers in whose hands it is entrusted.

One final point, however, is that even for T2, learner involvement was not consistent over the semester and did not manifest at the macro level of overall course design; rather, it was identifiable within specific activities. For example, learner selection of topics and materials was only witnessed in the pre-lesson presentations. Similarly, peer-evaluation/assessment was confined to specific points rather than longitudinal progress and mainly in the fairly simple manner of suggesting performance scores. Other aspects of LA that feature in the literature were not evidenced at all, such as student involvement in defining needs, objectives, progression or teaching methods (Borg \& Al-Busaidi, 2012; Reinders, 2010). Similar findings are reported elsewhere and are often attributed to institutional constraints such as prescribed curriculums (e.g. Borg \& Al-Busaidi, 2012; Wang \& Wang, 2016). With this in mind, the present findings can be interpreted in a promising light, as some teachers exercised their professional autonomy in identifying and creating opportunities for learner autonomy. Key to this is the teacher's genuine understanding and unshakeable trust in students' capacity for autonomy.

\section{References}

Barnard, R., \& Li, J. (Eds.). (2016). Language learner autonomy: Teachers' beliefs and

\footnotetext{
${ }^{7}$ Note that, like us, Little (2007a) challenges this position.
} 
practices in Asian contexts. IDP Publications Asia.

Benson, P. (2001). Teaching and researching autonomy in language learning. Longman.

Benson, P. (2003). Learner autonomy in the classroom. In D. Nunan (Ed.), Practical English language teaching (pp. 289-308). McGraw Hill.

Benson, P. (2011). Teaching and researching autonomy (2nd ed.). Pearson.

Borg, S. (2003). Teacher cognition in language teaching: A review of research on what language teachers think, know, believe, and do. Language Teaching, 36(2), 81-109. https:/doi.org/10.1017/S0261444803001903

Borg, S. (2018). Teachers' beliefs and classroom practices. In P. Garrett, \& J. Cots (Eds.), The Routledge handbook of language awareness (pp. 75-91). Routledge.

Borg, S. (2019). Language teacher cognition: Perspectives and debates. In X. Gao (Ed.) Second handbook of English language teaching (pp. 1149-1170). Springer.

Borg, S., \& Al-Busaidi, S. (2012). Learner autonomy: English language teachers' beliefs and practices. The British Council.

Borg, S., \& Alshumaimeri, Y. (2019). Language learner autonomy in a tertiary context:

Teachers' beliefs and practices. Language Teaching Research, 23(1), 9-38. https://doi.org/10.1177/1362168817725759

Camilleri, G. (1999). Learner autonomy: The teachers'views. Retrieved from http://archive.ecml.at/documents/pubCamilleriG_E.pdf

Candy, P. C. (1991). Self-direction for lifelong learning: A comprehensive guide to theory and practice. Jossey-Bass.

Chang, L. Y.-H. (2007). The influences of group processes on learners' autonomous beliefs and behaviors. System, 35(3), 322-337. https:/doi.org/10.1016/j.system.2007.03.001

Charmaz, K. (2006). Constructing grounded theory: A practical guide through qualitative analysis. Sage.

Chen, R.-Y., \& Hird, B. (2006). Group work in the EFL classroom in China: A closer look. RELC Journal, 37(1), 91-103. https:/doi.org/10.1177/0033688206063476

China MoE (2001a). 基础教育课程改革纲要(试行) [National curriculum reform for Basic Education (trial)]. Retrieved from http://www.gov.cn/gongbao/content/2002/content_61386.htm

Cortazzi, M., \& Jin, L. (1996). English teaching and learning in China. Language Teaching, 29(2), 61-80. https://doi.org/10.1017/S0261444800008351 
Creswell, J. W., \& Plano Clark, V. L. (2011). Designing and conducting mixed methods research (2nd ed.). Sage.

Dam, L. (1995). Learner autonomy 3: From theory to classroom practice. Authentik.

Dam, L. (2011). Developing learner autonomy with school kids: Principles, practices, results. In D. Gardner (Ed.), Fostering autonomy in language learning (pp. 47-58). Zirve University.

Farrell, T. S. C. and Ives, J. (2015). Exploring teacher beliefs and classroom practices through reflective practice: A case study. Language Teaching Research, 19 (5), 594610. https://doi.org/10.1177/1362168814541722

Feryok, A. (2010). Language teacher cognitions: Complex dynamic systems? System, 38(2), 272-279. https://doi.org/10.1016/j.system.2010.02.001

Glaser, B. G., \& Strauss, A. L. (1967). The discovery of grounded theory: Strategies for qualitative research. Aldine Publishing Company.

Gross, R. (2015). Psychology: The science of mind and behaviour (7th ed.). Hodder Education.

Harding, J. (2013). Qualitative data analysis from start to finish. Sage.

Ho, J., \& Crookall, D. (1995). Breaking with Chinese cultural traditions: Learner autonomy in English language teaching. System, 23(2), 235-243. https://doi.org/10.1016/0346251X(95)00011-8

Holec, H. (1981). Autonomy and foreign language learning. Pergamon.

Huang, J., \& Benson, P. (2013). Autonomy agency and identity in foreign and second language education. Chinese Journal of Applied Linguistics, 36(1), 7-28. https://doi.org/10.1515/cjal-2013-0002

Jin, L., \& Cortazzi, M. (2006). Changing practices in Chinese cultures of learning. Language, Culture and Curriculum, 19(1), 5-20. https://doi.org/10.1080/07908310608668751

Kohonen, V. (2010). Autonomy, agency and community in FL education: Developing sitebased understanding through a university and school partnership. In B. O'Rourke \& L. Carson (Eds.), Language learner autonomy: Policy, curriculum, classroom (pp. 3-28). Peter Lang.

Lee, S.H., Smith, D. and Sergueeva, K., 2016. What do students think about group work in business education? An investigation into the benefits, challenges, and student-suggested solutions. Journal of Education for Business, 91(7), pp. 380-386. https://doi.org/10.1080/08832323.2016.1237933

Little, D. (2007a). Introduction: Reconstructing learner and teacher autonomy in language education. In A. Barfield, S. H. L. Brown \& D. Little (Eds.), Reconstructing autonomy in 
language education: Inquiry and innovation (pp. 1-12). Palgrave Macmillan.

Little, D. (2007b). Language learner autonomy: Some fundamental considerations revisited. Innovation in Language Learning and Teaching, 1(1), 14-29. https://doi.org/10.2167/illt040.0

Martinez, H. (2008). The subjective theories of student teachers: Implications for teacher education and research on learner autonomy. In T. E. Lamb \& H. Reinders (Eds.), Learner and teacher autonomy: Concepts, realities, and responses (pp. 103-124). John Benjamins.

Nunan, D. (1997). Designing and adapting materials to encourage learner autonomy. In P. Benson \& P. Voller (Eds.), Autonomy and independence in language learning (pp. 192203). Longman.

Peterson, M. (2012). EFL learner collaborative interaction in Second Life. RECALL, 24(1), 20-39. https://doi.org/10.1017/s0958344011000279

Reinders, H. (2010). Towards a classroom pedagogy for learner autonomy: A framework of independent language learning skills. Australian Journal of Teacher Education, 35(5), 40-55. https://doi.org/10.14221/ajte.2010v35n5.4

Robson, C. (2002). Real world research: A resource for social scientists and practitionerresearchers. Blackwell.

Seidel, J. V. (1998). Qualitative data analysis. http://www.qualisresearch.com/qda paper.htm

Shu, D.-F. (2004). 外语教学改革: 问题与对策/ELT in China: Problems and suggested solutions. Shanghai Foreign Language Education Press.

Shu, D.-F., \& Hua, W.-F. (2009). 中国外语教学理论研究六十年:回顾与展望 [Foreign language teaching theories in China in the last 60 years: Reviews and Prospects]. 外语教 学/ Foreign Language Education, 30(6), 37-44.

Storch, N. (2001). How collaborative is pair work? ESL tertiary students composing in pairs. Language Teaching Research, 5(1), 29-53. https://doi.org/10.1191/136216801666650977

Strauss, A. L. (1987). Qualitative analysis for social scientists. Cambridge University Press.

Trebbi, T. (2003). Curriculum development and learner autonomy in the foreign language classroom: Constraints and possibilities. In D. Little, J. Ridley \& E. Ushioda (Eds.), Learner autonomy in the foreign language classroom: Teacher, learner, curriculum and assessment (pp. 166-184). Authentik.

Voller, P. (1997). Does the teacher have a role in autonomous learning? In P. Benson \& P. Voller (Eds.), Autonomy and independence in language learning (pp. 98-113). Longman. 
Wang, Q. \& Ma, X. (2009). Educating for learner-centredness in Chinese pre-service teacher education. Innovation in Language Learning and Teaching, 3(3), 239-253. https://doi.org/10.1080/17501220903404475

Wang, Y., \& Wang, M.-X. (2016). Developing learner autonomy: Chinese university EFL teachers' perceptions and practices. In R. Barnard \& J. Li (Eds.), Language learner autonomy: Teachers' beliefs and practices in Asian contexts (pp. 23-42). IDP Publications Asia.

Watanabe, A. (2017). Reflective practice as professional development: Experiences of teachers of English in Japan. Multilingual Matters.

Woods, D., \& Çakır, H. (2011). Two dimensions of teacher knowledge: The case of communicative language teaching. System, 39(3), 381-390. https://doi.org/10.1016/j.system.2011.07.010

$\mathrm{Xu}, \mathrm{Y}$., \& Wong, H. (2011). School-based curriculum development in China. Chinese Education \& Society, 44(4), 44-63. doi:10.2753/ced1061-1932440403 